\title{
How to Reform Business Licenses
}

.

Investment Climate Advisory Services I World Bank Group
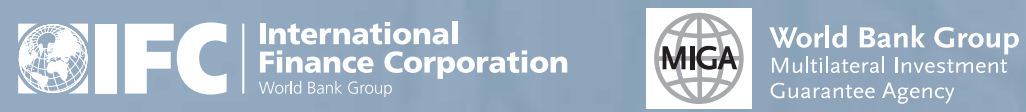

(4) THE WORLD BANK 


\section{How to Reform Business Licenses}

\section{June 2010}

Investment Climate Advisory Services of the World Bank Group

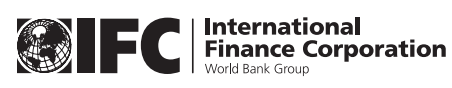


(92010 The World Bank Group

1818 H Street, NW, Washington D.C., 20433

All rights reserved

Manufactured in the United States of America

First Printing: June 2010

This information, while based on sources that the World Bank Group considers to be reliable, is not guaranteed as to accuracy and does not purport to be complete.

The findings, interpretations, and conclusions expressed in this work are those of the authors and do not necessarily reflect the views of the Board of Executive Directors of the World Bank or the governments of the countries which they represent. The information in this work is not intended to serve as legal advice.

The World Bank Group does not guarantee the accuracy of the data included in this work and accepts no responsibility for any consequences of the use of such data.

The denominations and geographical names in this publication are used solely for the convenience of the reader and do not imply the expression of any opinion whatsoever on the part of the International Finance Corporation, the World Bank, or other affiliates concerning the legal status of any country, territory, city, area, or its authorities, or concerning the delimitation of its boundaries or national affiliation.

\section{Rights and Permissions}

The material in this publication is copyrighted. Copying and/or transmitting portions or all of this work without permission may be a violation of applicable law. The World Bank Group encourages dissemination of its work and will normally grant permission to reproduce portions of the work promptly.

For permission to photocopy or reprint any part of this work, please send a request with complete information to the Copyright Clearance Center Inc., 222 Rosewood Drive, Danvers, MA 01923, USA; telephone: 978-750-8400; fax: 978-750-4470; online at: www.copyright.com.

\section{About the Investment Climate Advisory Services of the World Bank Group}

The Investment Climate Advisory Services of the World Bank Group helps governments implement reforms to improve their business environments and encourage and retain investment, thus fostering competitive markets, growth, and job creation. Funding is provided by the World Bank Group (IFC, MIGA, and the World Bank) and over 15 donor partners working through the multidonor FIAS platform. 


\section{Acknowledgements}

The lead author of this handbook is Laurent Corthay from the Investment Climate Advisory Services of the World Bank Group. The handbook was co-authored by Lars Grava, Stephen Rimmer, and Delia Rodrigo from the Investment Climate Advisory Services. The project was supervised by Peter Ladegaard, Product Leader (Business Operations), Investment Climate Advisory Services. Early versions of the handbook benefitted from the contributions of Desiree Allen Aidoo, Florentin Blanc, Christine Bowers, Jackie Coolidge, Sanjar Ibragimov, Domagoj Ilic, Laura Kaliszewski, Sarah Kitakule, Petter Lundkvist, Lan Van Nguyen, Ivan Nimac, Kristtian Rada, Patricia Steele, Ksenija Vidulic, and Wendy Werner. 


\section{List of Abbreviations}

$\begin{array}{ll}\text { ACTAL } & \text { Advisory Board on Administrative Burden (Holland) } \\ \text { BRB } & \text { Business Regulations Bill } \\ \text { CEO } & \text { Chief Executive Officer } \\ \text { COFEMER } & \text { Comisión Federal de Mejora Regulatoria (Mexico) } \\ \text { DFID } & \text { Department for International Development (United Kingdom) } \\ \text { EDBM } & \text { Economic Development Board of Madagascar } \\ \text { FIAS } & \text { Foreign Investment Advisory Service } \\ \text { GTZ } & \text { Gesellschaft für Technische Zusammenarbeit (Germany) } \\ \text { ICA } & \text { Investment Climate Assessments } \\ \text { IFC } & \text { International Finance Corporation } \\ \text { MIGA } & \text { Multilateral Investment Guarantee Agency } \\ \text { M\&E } & \text { Monitoring and Evaluation } \\ \text { NGO } & \text { Nongovernmental Organization } \\ \text { OECD } & \text { Organization for Economic Co-operation and Development } \\ \text { RIA } & \text { Regulatory Impact Analysis } \\ \text { RRS } & \text { Regulatory Reform Strategy } \\ \text { RRU } & \text { Regulatory Reform Unit } \\ \text { SCM } & \text { Standard Cost Model } \\ \text { UDE } & \text { Unidad de Regulación Económica (Mexico) } \\ \text { WBG } & \text { World Bank Group }\end{array}$




\section{Contents}

Index of Boxes ................................................... vii

Index of Annexes .............................................. vii

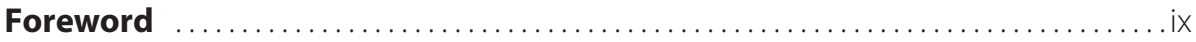

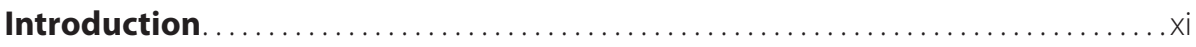

Chapter 1: Project Preparation and Diagnostics $\ldots \ldots \ldots \ldots \ldots \ldots \ldots \ldots \ldots \ldots \ldots$

1.1: Desk Review of Available Diagnostics and Benchmarking ................. 1

1.2: Stakeholder and Political Economy Analysis........................... 2

1.3: Preliminary Diagnostic to Assess Potential Scope for Reform ................ 5

1.4: Making the Case for Reform: Compelling Presentation to the Government.... . 7

1.5: Obtaining a Letter of Request from Clients.......................... 7

1.6: Elaborating a Media and Communications Strategy ................... 8

Chapter 2: Establishing a Tailored and Focused Reform Program ................. 11

2.1: Political Decision Showing High-Level Endorsement.................... 11

2.2: Outreach Strategy with Executive Bodies and Regulatory Agencies.......... 12

2.3: Building an Inventory of all Existing Licenses and Authorizations........... 12

2.4: Using the Standard Cost Model to Benchmark Compliance Burden ........... 14

2.5: Setting Quantitative Reform Targets ............................. 16

2.6: Establishing a Reform Committee with Explicit Mandate ................... 17

2.7: Validating Inventory Findings with Owning Agencies and the Private Sector . . 18

2.8: Identifying Quick Wins to Spur Reform Momentum ...................... 20

2.9: Selecting High-Priority Licenses . ................................ 21 
2.10: Initial Drafting of a Medium-Term Regulatory Reform Strategy. .

2.11: Identifying a Strategy for Legal Implementation of Reforms.............. 25

2.12: Designing a Monitoring and Evaluation Framework $\ldots \ldots \ldots \ldots \ldots \ldots \ldots . . \ldots 26$

Chapter 3: Review of the Licenses....................................... 29

3.1: Designing a License Information Database ........................... 29

3.2: Engaging with Regulatory Agencies in Making Reform Proposals ........... 30

3.3: Review of Licenses by the Reform Committee .......................... 31

3.4: Paying Specific Attention to Sectoral Reviews ........................... 34

3.5: Rationalizing the System of Local Regulations, Fees and Taxes ............. 34

3.6: Preparing Decision Memos for Government Approval ...................... 36

3.7: Political and Communications Strategy to Support Adoption of Reform...... 36

Chapter 4: Reform of the Licensing System................................ 39

4.1: Legal Implementation of Decisions . .............................. 39

4.2: The Last Mile: Ensuring Reforms are Effective in Practice .................. 40

4.3: Introducing an Electronic Registry of All Valid Licenses.................... 41

4.4: Monitoring \& Evaluation: Project Completion, Evaluation and Lessons Learned ............................................... 43

Chapter 5: Broadening the Scope of Reform Beyond Licensing ................ 45

5.1: Implementing the Medium-Term Regulatory Reform Strategy .............. 45

5.2: Establishing a Regulatory Reform Unit at the Core of Government .......... 46

5.3: Ensuring Quality of Future Regulations: Regulatory Impact Analysis..........48

5.4: Exploring the Need for Business Regulations Bill ....................... 49

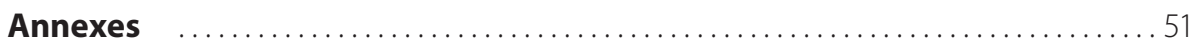

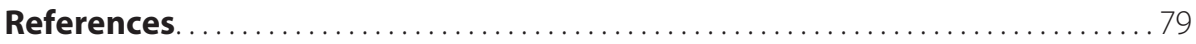




\section{Index of Boxes}

Box 1: Investment Climate Diagnostic Tools and Their Relevance for Business

Licensing Reforms .......................................... 2

Box 2: Checklist of Components for Stakeholder Analysis ....................... 3

Box 3: Typical Stakeholders in Investment Climate Reforms .................... 4

Box 4: Features of Good Practices for Licensing Administration and Practice . . . . . . . 6

Box 5: Considerations for the Design of a Communications Strategy ............... 8

Box 6: Typical Categories of Activities Subject to Licensing..................... 13

Box 7: Standard Cost Model ............................................... 15

Box 8: Determining the Appropriate Burden Reduction Target . . . . . . . . . . . . . . 17

Box 9: Typical Responsibilities of the Chairperson ........................ 18

Box 10: Three Dimensions for Choosing Reform Committee Members.............. 19

Box 11: Why a Medium-term Regulatory Reform Strategy? ..................... 23

Box 12: Features of Good Regulatory Administration and Practices ............... 24

Box 13: Using Monitoring and Evaluation Indicators in Business Licensing Projects . . . 27

Box 14: How to Get Baseline Data When None is Readily Available................. 28

Box 15: The "Reversal of the Burden of Proof" Principle...................... 30

Box 16: Reform Architecture in Madagascar .................................. 31

Box 17: Checklist of Key Features of Good Regulatory Design ................... 33

Box 18: Principles for Imposition of Licensing Fees and Charges ................ 35

Box 19: Principles and Responsibilities for an E-registry System . ................ 42

Box 20: Typical Information to Enter in an E-registry....................... 42

Box 21: Institutionalizing Regulatory Reform —The Case of Mexico............... 47

Box 22: Seven Key Steps in a Regulatory Impact Analysis. ...................... 49 


\section{Index of Annexes}

Annex 1: Summary Table: Standard Stages and Steps to Implement Business Licensing Reform .................................... 53

Annex 2: Information Collection Template for Licenses and Permits ................ 60

Annex 3: Terms of Reference: Inventory of Business Licenses - Local Consultant . . . . 63

Annex 4: Terms of Reference: Standard Cost Model Benchmarking of Compliance Costs.

Annex 5: Terms of Reference: Chairperson of the Reform Committee ............. 72

Annex 6: Outline for Decision Memos of the Reform Committee .................. 75 


\section{Foreword}

Reforming business licenses is part of a suite of products delivered by the World Bank Group's Investment Climate Advisory Services, under the Business Operations practice. The Business Operations team has the responsibility of bringing such products as licensing, inspections, and construction permits to maturity, through a combination of knowledge management and pilot projects, with the objective of developing products that are scalable, easily replicable, and tailored to enhance the impact of IFC Advisory Services.

The approach to reforms highlighted in this handbook fits into the broader Policy Framework for Business Licensing Reform and Simplification'. The Framework Paper provides the context for business licensing practices; establishes the key principles and concepts underpinning licensing; and gives an overview of licensing reform objectives, issues, and processes. It includes an overall introduction to the use (and abuse) of business licenses, and a further elaboration on the way business licensing reforms can be organized.

This handbook is part of a suite of knowledge management products dedicated to business licensing, which also includes:

- Sector studies on business licensing in tourism, mining, and building permits

- A policy note on reforming local taxes, regulations and the business environment

- Guidance on application and modification of the Standard Cost Model (SCM) in developing countries

- Guidance on monitoring and evaluation (M\&E) for licensing reforms

- A suite of references under the Better Regulation for Growth program ${ }^{2}$ including papers and country case studies

- Regional trainings on business licensing reforms

\footnotetext{
1 See World Bank Group (2010).

2 Available at www.fias.net/ifcext/fias.nsf/Content/BRG_Home_page
} 
These publications and an online version of this handbook will be made available publicly over the coming months on the Investment Climate Advisory Services' external website.

\section{Peter Ladegaard}

Business Operations Product Leader

Investment Climate Advisory Services

The World Bank Group

\section{Laurent Corthay}

Lead author, Private Sector

Development Specialist

Investment Climate Advisory Services

The World Bank Group 


\section{Introduction}

\section{Purpose}

This handbook is based on experiences gained in implementing comprehensive business licensing reforms. It aims to provide detailed information and guidance to reform practitioners on implementing fast-track, top-down licensing and regulatory reform projects. The handbook's structure follows the process underpinning such reforms, taking readers step-by-step through the successive stages of reforms. Additionally, it is complemented by a range of documents and tools that have been used in recent projects and that can be readily picked up and tailored to country specifics.

\section{Definition and principles}

Licensing is a commonly used type of regulation, by which governments regulate businesses' entry into markets and operation within markets. This can involve the use of permits, certification, and other forms of authorizations and notifications. To obtain the required licenses, businesses typically have to comply with a series of legal requirements, which can impose substantial administrative and financial burdens on their activities. Across the developing world, close to 15 percent of firms consider business licenses and permits as a major constraint to doing business ${ }^{3}$. A sound business licensing system plays a critical role in creating a regulatory environment that is conducive to doing business, creating jobs and investment.

The Framework Paper on Business Licensing Reform and Simplification establishes the general framework and principles guiding the approach detailed in this handbook ${ }^{4}$. It provides the rationale for government regulation, for licensing as a regulatory tool, as well as the principles and assumptions underpinning the Investment Climate Advisory Services'approach to licensing reforms. The approach is designed to provide solutions to systemic problems encountered in many client countries, where the licensing systems have often grown out of control, across sectors and levels of government.

\section{Comprehensive versus narrowly focused reforms}

The approach presented here involves a top-down, comprehensive reform process, similar to the so-called "guillotine" or "staged-repeal" approaches. In practice, reforms are not always

\footnotetext{
3 See www.enterprisesurveys.org.

${ }^{4}$ Available at www.fi as.net/ifcext/fi as.nsf/Content/BRG_Home_page
} 
carried out in a comprehensive way, but may adopt a more narrow focus. However, there is much to be gained from a comprehensive approach that targets the whole licensing system.

In particular, there is an efficiency argument supporting that view, whereby one process achieves what would require multiple interventions otherwise, with high transaction costs. Additionally, on efficacy grounds, bold successes are more likely when not giving in to special interests. Finally, a comprehensive approach makes it possible to address some of the key long-term, systemic issues with the regulatory system (not just licenses), thus ensuring a healthy flow of future regulations.

\section{Structure of the handbook}

This handbook is written for business regulation practitioners. It aims to provide reformers with detailed information and guidance on how to implement fast-track, top-down licensing and regulatory reform projects. Its structure follows the process underpinning such reforms, taking readers step-by-step through the successive stages of reforms. Five main stages are involved in the preparation and rollout of a comprehensive, top-down business licensing reform project:

- Project design and diagnostic

- Establishing a tailored and focused reform program

- Reviewing the licenses

- Reforming the licensing regime

- Broadening the scope of reform beyond licensing

\section{How to use this handbook}

These five stages constitute the backbone of this handbook, each having its own chapter. Every stage is further broken down into key steps that need to be taken to achieve project objectives. Where relevant, the step's description is complemented by project documents and resources that are geared to provide project teams with drafts that can be tailored and readily applied in their projects. Attachments include documents, such as terms of reference, information-gathering templates, examples of decrees of different countries, as well as references to other useful resources. At the end of this handbook, a Summary Table ${ }^{5}$ of the stages and steps is provided to give the reader a condensed overview, highlighting for each step, its specific purpose, the entity in charge of carrying it out, the key outputs, and examples or issues of interest.

The attachments included here come from projects that have been implemented recently by the World Bank Group. One of the objectives of this handbook is to centralize

\footnotetext{
5 See Annex 1 for the Summary Table.
} 
knowledge gathered by World Bank Group teams and ensure cross-fertilization between regions. The Business Operations team is therefore always keen to consider project documents other reformers may have used, that could help inform other practitioners ${ }^{6}$.

This print version gathered essential documents and references available as it went to press. It has been prepared in print format for cases where a hard copy is the more practical format. It is planned that an online version accessible to all users will be made public over the coming months.

\footnotetext{
6 Please e-mail Laurent Corthay at Icorthay@worldbank.org for questions and comments.
} 



\section{Chapter 1: Project Preparation and Diagnostics}

This first stage involves conducting a preliminary assessment of the licensing system through a review of existing diagnostic work, as well as the scoping mission in the country. In this stage, the potential for reform as well as key stakeholders will be identified, and a broad implementation plan will be drawn. Finally, this stage will seek to build support for the proposed reform and establish a working relationship with a direct counterpart in government.

\subsection{Desk Review of Available Diagnostics and Benchmarking}

In many cases, a wide range of diagnostic tools is already available, providing data on a series of investment climate issues (see Box 1). These should be reviewed early on, with the following questions in mind:

- Are business regulations a serious constraint for businesses, as compared to other investment climate issues (e.g. political stability, access to infrastructure, access to markets, etc.)?

- Are business licenses a serious constraint for businesses, as compared to other administrative and regulatory issues (e.g. tax administration, inspections, labor regulations, etc.)?

- Is the existing licensing system effective in protecting safety, health, environment and other public interest objectives?

- Are there any sector-specific issues related to licensing that require particular attention?

- What investment climate reform efforts have already been undertaken, or are currently underway? When? By whom? What were the outcomes?

A paper by Djankov (2007) reviews recent major efforts in the field of measuring the ease of enterprise, and provides useful suggestions on how to use the existing indicators. 


\section{Box 1 Investment Climate Diagnostic Tools and Their Relevance for Business Licensing Reforms}

\section{World Bank Group resources}

- The World Bank's Investment Climate Assessments (ICAs) are based on Enterprise Surveys (www.enterprisesurveys.org) and other sources of information. These are helpful tools for an understanding of the relative magnitude of licenses vis-à-vis other burdens, although ICAs usually do not go into detail regarding the burden imposed by individual licenses. The ICAs can offer insight into the burden of regulations in a country, but this information may not be located in a single section and each report should be scanned thoroughly for relevant information. If the methodology used in the enterprise survey in a given country is consistent and comparable over several years, trends can be identified.

- The Doing Business indicators are available at www.doingbusiness.org. While the Doing Business report does not address licenses in the broad sense used in this handbook, there are a number of indicators that can be used to analyze the burden of licenses and related regulatory problems, including "Starting a Business," "Dealing with Construction Permits," "Paying Taxes," "Trading Across Borders."

- FIAS Administrative Barriers Studies have been prepared for a number of countries and in some cases go into significant detail on the licensing regime, including diagnostic and reform recommendations. Findings from these studies have triggered licensing reforms in different countries. Administrative Barriers studies are accessible for internal use, and are sometimes publicly posted. (www.fias.net).

- Business Environment Snapshots are handbooks to business environment indicators, laws, and World Bank Group project information for 151 countries. Business Environment Snapshots can be accessed at (http://rru.worldbank.org/besnapshots).

- Other World Bank Group data sources may include regional tools such as the Business Environment and Enterprise Performance Surveys, as well as country-specific Economic and Sector Work such as Country Economic Memorandum, and others.

\section{Other data resources}

- Economist Intelligence Unit's country reports. A subscription is required to access the reports. These provide useful and up-to-date information on regulatory policies and practices in a given country, in addition to other economic and political information.

- Fraser Institute's Economic Freedom of the World

- Heritage Foundation's Index of Economic Freedom

\subsection{Stakeholder and Political Economy Analysis}

The main objective in this step is to identify and prioritize stakeholders early on, and identify one or several potential reform champions to become the main counterparts of the project. This is an important step in organizing an ensuing scoping mission, as it will help establish a list of key meetings needed. 
Government statements and publications outlining the country's policy on developing the private sector and attracting investments should be scrutinized, to understand the government's priorities and strategic directions in that regard.

For a comprehensive coverage of stakeholder analyses, please refer to IFC (2007). For quick reference points, please find in Box 2 a checklist of components for a stakeholder analysis, as well as a list of typical stakeholders in investment climate or business environment reforms.

\section{BOX 2 Checklist of Components for Stakeholder Analysis}

- List of stakeholders surveyed (interviews, focus groups, etc.)

- Identification of stakeholders by category (key, primary, secondary) and descriptions of those groups

- Discussion of stakeholder perceptions that highlights shared and differing opinions

- Refined list of perceived stakeholder interests and an evaluation of potential impact on project

- Evaluation of stakeholders' level of support for, or opposition to, reform

- Evaluation of stakeholders' level of influence on project success

- Identification of key concerns or expectations of each stakeholder group

Source: IFC (2007).

Business licensing reforms typically involve a wide range of stakeholders, from both the public and private sectors. The categorized checklist ${ }^{7}$ provided in Box 3 below, lists the key players commonly involved in regulatory reforms that can serve as reference points in the preparation of the stakeholder outreach strategy.

One key element in this step is to identify adequate champion(s), among the strong, influential proponents of the reforms. Successful reforms will require institutional champions with the technical capacity and the willingness to battle with the many vested interest groups opposed to changes. As highlighted in Kikeri et al. (2006), long and complicated reform processes require the endurance and conviction of a group of committed individuals who persist with policy changes, despite changes in the political landscape. Champions should have close ties or influence with the highest possible level of political decision-making. Examples include:

- Mexico ${ }^{\mathbf{8}}$ : a small group of technocrats leading the first deregulation unit (UDE) became a major lobbying force, which later became a commission backed by law

\footnotetext{
IFC Small and Medium Enterprise Department; IFC (2007).

8 See also Box 21 for more on the case of Mexico in institutionalizing regulatory reforms and the role of UDE.
} 


\section{BOX 3 Typical Stakeholders in Investment Climate Reforms}

\begin{tabular}{|c|c|c|c|}
\hline Private Sector & Public Sector & Civil Society & $\begin{array}{l}\text { International } \\
\text { Community }\end{array}$ \\
\hline $\begin{array}{l}\text { - Local and foreign } \\
\text { investors }\end{array}$ & - President's office & $\begin{array}{l}\text { - National and } \\
\text { local non- } \\
\text { governmental } \\
\text { organizations }\end{array}$ & $\begin{array}{l}\text { Multilateral } \\
\text { development } \\
\text { partners }\end{array}$ \\
\hline $\begin{array}{l}\text { - Small and medium- } \\
\text { sized businesses }\end{array}$ & $\begin{array}{l}\text { - National and } \\
\text { local public } \\
\text { institutions }\end{array}$ & - Trade unions & - Foreign governments \\
\hline - Large corporations & $\begin{array}{l}\text { - Ministers and } \\
\text { advisors }\end{array}$ & - Academia & $\begin{array}{l}\text { - International } \\
\text { development NGOs }\end{array}$ \\
\hline $\begin{array}{l}\text { - Financial } \\
\text { institutions }\end{array}$ & - Civil servants & $\begin{array}{l}\text { - National, local, } \\
\text { and international } \\
\text { media }\end{array}$ & \\
\hline $\begin{array}{l}\text { Business } \\
\text { membership } \\
\text { organizations } \\
\text { (business } \\
\text { associations, } \\
\text { chambers of } \\
\text { commerce)* }\end{array}$ & - Parliament & $\begin{array}{l}\text { - Citizen advocacy } \\
\text { groups* }\end{array}$ & \\
\hline $\begin{array}{l}\text { - Professional } \\
\text { organizations* }\end{array}$ & - Political parties & $\begin{array}{l}\text { - General } \\
\text { population }\end{array}$ & \\
\hline $\begin{array}{l}\text { - Individual business } \\
\text { leaders }\end{array}$ & $\begin{array}{l}\text { Investment } \\
\text { promotion } \\
\text { or economic } \\
\text { competitiveness } \\
\text { commissions } \\
\text { and councils }\end{array}$ & & \\
\hline
\end{tabular}

* Note: stakeholder intermediaries

(COFEMER), functioning as a regulatory reform unit, at the core of government. UDE and COFEMER leveraged the support and influence of major industrial players and other private organizations by giving them a seat on the board of the Deregulation Council.

- Korea: a group of presidential advisers chosen from outside the traditional bureaucracy championed the 1998 regulatory reforms.

- Hungary: a small, ad hoc task force in the Ministry of Finance closely linked to the Prime Minister's office led the 1994 regulatory reforms. 
Identifying champions is not a one-time activity, but should be an ongoing task for project teams, as political and economic conditions may change rapidly, thus affecting stakeholders' interests and relative influence. Comprehensive reforms may not happen in the absence of strong champions.

Kikeri et al (2006) provides more on this - including further references - based on the study of six successful regulatory reform cases. See also Criscuolo, Palmade (2008) for more on the critical role played by reform teams and champions in successful regulatory reforms.

\subsection{Preliminary Diagnostic to Assess Potential Scope for Reform}

The preliminary scoping diagnostic aims to:

- verify findings from the consultation of previous diagnostics and benchmarking reports/data, as well as make a preliminary assessment of the quality of the licensing regime and its main weaknesses;

- confirm the government's demand, priorities and capacity to drive the reform;

- establish a working relationship with a counterpart in government;

- outline a preliminary action plan for a proposed business licensing reform which is tailored to the country's needs and context.

To assess the quality of licensing administration and practice, the checklist in Box 4 below may be used in the initial diagnostic phases, as well as later on in the review of licenses and licensing practices, to identify where the licensing regime may feature deficiencies that require attention. The checklist is ordered around the four main features of the process for obtaining and administering licenses.

What about inspections?

This handbook is conceived with a specific focus on business licensing practices and administration. It does not target the reform of inspections system, at least not in the first stages of a business licensing reform project. This may come as a surprise, since in some ways, licensing (i.e. the granting of an ex ante authorization to perform a specific activity) and inspections (i.e. the verification ex post that the activity is performed according to standards) are two sides of the same medal. Both need to work well in order to ensure a regulatory environment that is conducive to investment by reducing transaction costs, providing certainty and encouraging healthy competition.

This handbook takes a staged approach, which starts with a comprehensive, fast-track reform of the licensing system, followed by the introduction of mechanisms that will ensure 


\section{BOX 4 Features of Good Practices for Licensing Administration and Practice}

1. Search and application

- Businesses should be able to obtain in an easy and timely manner clear and comprehensive guidance material and well-designed forms. They should be able to easily communicate with the regulator.

- Businesses should be informed of the steps involved and the time likely to be taken by the regulator in assessing and responding to their applications for licenses.

2. Approval

- Regulators should assess and respond to applications for licenses in a timely manner, and follow relevant policies and guidelines.

- Assessment should employ risk-based methodology.

- Decisions should be fully documented and subject to a credible appeals process.

- Internal processes should minimize scope for conflict of interest and corruption (such as review of decisions by peers or more senior staff).

3. Conditions

- Business should have a clear understanding of licensing conditions, obligations, and their rights.

- License conditions and obligations should be the minimum necessary to ensure compliance.

- Regulators should be mindful of compliance burdens on business and have effective strategies to minimize compliance burdens.

- Regulators should have internal systems and processes to monitor and report on compliance with licensing requirements.

- Compliance monitoring should include a clear documented strategy, risk-based work program, and timely, evidence-based and objective compliance assessment processes.

4. Enforcement

- Enforcement should be commensurate with the risks generated by non-compliance and the compliance history of the business.

- Regulators' response should be timely, proportionate, lawful, and properly documented.

- Enforcement strategies should be effective in ensuring compliance but not impose on business unnecessary obligations, costs or risks.

- There should be a clear plan to manage and assist the return of the business to compliance.

- Strategies should be in place to minimize the risk of corruption, including clear and credible appeals processes (such as review by a higher authority and judicial review).

Sources: OECD (1995), OECD (2002); Bureau of Industry Economics (1996a); Bureau of Industry Economics (1996b). 
that the stock of existing licenses, as well as the flow of future licenses, match standards of good regulatory quality. The proposed approach would recommend exploring the potential for the reform of the inspections regime once early successes of the licensing reform have been achieved. Indeed, licensing may be used as one of the better entry-points that can lead to broader and deeper reforms of the regulatory regime.

Sections 2.10 and 5.1 deal with drafting and implementing a medium-term regulatory reform strategy. This would possibly include the improvement of the inspection system as a key objective. Also, more details can be found in IFC (2006b), which provides guidelines and good practices for business inspections reforms.

\subsection{Making the Case for Reform: Compelling Presentation to the Government}

At the end of the scoping mission, preliminary findings and the proposed action plan should be presented to key government officials to get their support.

Key arguments underpinning a comprehensive, systemic reform approach, as opposed to more narrowly focused reforms, include?

- Efficiency: evaluating all licenses through one reform process, proposing one reform package, and implementing a series of changes at one time, through one process, rather than setting up a new reform machinery, with heavy transaction costs every time.

- Efficacy: not giving in to special interests, which will emerge for almost every license or sector where reforms are proposed. A piecemeal approach (e.g., one sector after the other) gives special interests much more leverage to impede reforms from happening.

- Addressing systemic issues: comprehensive approach allows for clean-up of the whole system, and the establishment of tools (e-registry) and institutions such as a regulatory reform unit, which help solve some of the systemic problems that led to poor business regulations (fixing the stock of valid regulations through the registry, and ensuring a healthy flow of future regulation through the regulatory reform unit).

\subsection{Obtaining a Letter of Request from Clients}

As is standard practice for all World Bank Group projects, an official letter of request from government counterparts should be obtained to officially launch the project. This letter is generally signed by the lead Minister (could be Finance or Economy, Trade \& Industry, or

\footnotetext{
9 For more on this, please refer to World Bank Group (2010).
} 
equivalent), requesting specific assistance to design and support implementation of the licensing reform.

Practice in transition and frontier countries suggests that the requesting party should be as high in the political hierarchy as possible to increase the chances of success. When feasible, project teams should explore the possibility of engaging with the President's office (or the Vice-Prime Minister's office). A high level of political commitment should provide strong incentives to the regulatory agencies and ministries affected by the reform activities to take an active part in the process. This could be considered as a first signal to them.

\subsection{Elaborating a Media and Communications Strategy}

Communication plays an essential role in ensuring the success of policy and administrative reforms, and licensing is no exception. Often, however, technical reforms tend to overlook this fact and rely on limited, traditional communication channels only, such as speeches by government officials and other reports published in the legal gazette (but who really reads it?), and posting changes on government Web platforms. Much more can be done to reach the audiences that matter - businesses and ultimately citizens - to ensure that the beneficiaries are well informed about the reform, understand how it will impact them, and can share their views to help shape it or future reforms.

Box 5 lists key considerations that should be taken into account when designing a strategic communications strategy ${ }^{10}$. Please also refer to IFC (2007) for a detailed handbook

\section{BOX 5 Considerations for the Design of a Communications Strategy}

- Selecting spokespersons from the business community. Using government officials as the main spokespeople for successful regulatory reforms is ineffective, as they generally relate less to businesses and their priorities than other businesspeople do. To effectively convey messages about what can be gained from the reforms, select entrepreneurs and use them in the information campaigns. The message is more powerful if conveyed by a beneficiary: this is why shampoo commercials show people with long hair, not the CEO of the shampoo company.

- Using mass communication channels. Using specialized "passive" information channels (such as the legal gazette) is unlikely to reach the targeted audience. Sharing information about the benefits of the reforms, as well as the results of business surveys on remaining obstacles is best done through the mass media. News stories could feature entrepreneurs, present new statistics, and describe what current reforms are taking place. To do this effectively, communications staff could be hired with the reform committee.

\footnotetext{
10 This list is drawn and adapted from World Bank Group (2007) pp. 13-14.
} 


\section{BOX 5 (continued)}

- Organizing public events. Invite entrepreneurs to talk about existing problems, as well as what improvements they see. Results from the Standard Cost Model and the business surveys could be presented at these events. Invite the media and always leave ample time for questions. Do not organize only with the business associations; invite entrepreneurs directly. Communication works both ways in such events; they also allow businesses to explain their priorities to government.

- Using comparisons with other countries. Businesses and citizens are generally patriotic, regardless of how they regard their government's effort to reform. Comparisons with the regulatory burdens in other countries, especially in areas where the country is reforming, would catch the attention of entrepreneurs and media. They are especially good for newspaper (print) stories where figures can be shown.

- Talk about future reforms. Start communicating early on about the expected results and sustain the message as the reform progresses. The longer the message stays in the news, the more likely it is that businesses will notice. The communication just needs to be clear and direct on when the announced measures will be implemented. This is not just good marketing. Reforms are only useful if businesses learn how to take advantage of them. And businesses will only learn if the news has reached them.

Source: World Bank Group (2007).

on strategic communications for business environment reforms. Also, IFC (2008) Using Communications in Tax Simplification Projects, provides a shorter note with cases from business taxation reforms in two countries, which provides useful lessons learned, in spite of not being licensing-specific. 



\section{Chapter 2: Establishing a Tailored and Focused Reform Program}

This stage establishes the key elements of the licensing reform program, taking the country's specific needs into account. One central element is the elaboration of a comprehensive inventory of existing licenses, defined in broad terms. This inventory and its findings constitute the main data upon which analyses and review will be conducted. It will also help establish a baseline for the project, and a quantitative reform target to be achieved by the end of the project.

This stage will also seek to establish the so-called "reform infrastructure," including a committee with a strong political mandate that will have the responsibility and authority to conduct the reform, as well as identify a legal strategy for implementation. A comprehensive licensing reform requires a dedicated, cross-ministerial group of technical experts, at the core of government, with a strong support from the top of the government's pyramid.

\subsection{Political Decision Showing High-Level Endorsement}

A political decision containing the key elements of the reform should be made public. This may be through a cabinet decision or any other way that shows the highest level of commitment. The purpose of the decision is to signal to all licensing authorities the high level of support for the reform and request cooperation during the review process. The decision should include:

- scope of work and reform infrastructure (i.e., the fact that a reform committee will be established to implement the reform and its mandate);

- endorsement of the criteria for the review of licenses (i.e., legality, efficiency, necessity, and business-friendliness); and

- request for cooperation of all licensing authorities to the reform process (reversing of burden of proof requires active participation by all authorities issuing licenses). 


\subsection{Outreach Strategy with Executive Bodies and Regulatory Agencies}

To secure a high level of participation among all the line ministries and regulatory agencies involved in the licensing system, the government's endorsement of the reform (including elaboration of the inventory, quantification and streamlining objective of the system) should be clearly communicated with them.

At a minimum, the goal is to ensure that all the data necessary to build the inventory can be obtained from the relevant parts of the administration. However, their active involvement in the reform process (including reviewing the existing regulations and implementing a streamlined system) will be crucial. It is therefore important to engage with the regulatory bodies early on, and prepare the groundwork for the upcoming reform activities, such as the creation of a cross-ministerial reform committee.

\subsection{Building an Inventory of all Existing Licenses and Authorizations}

In many countries, there is no overview of all the business licenses existing in the system. A comprehensive inventory must therefore be built from scratch, in order to get a complete list of existing business licenses, and capture essential data on each license. The information thus gathered will allow for:

- calculating the total administrative burden imposed by the system on the economy;

- informing the review of all the licenses (i.e., conducting the "guillotine" review); and

- serving as the basis for developing an e-registry at a later stage.

A standard template ${ }^{11}$ has been developed to allow for fact finding, and to provide consistent and systematic information for each license. The template should be tailored to the country context (especially with respect to data availability).

Information should be gathered by a trained interviewer from relevant government officials and subjected to stakeholder (including business representative) validation.

Filling out the template is often performed by a local consulting firm, preferably one experienced in helping businesses obtain a wide array of licenses. The ideal local consulting firm will also have experience in conducting surveys, and an understanding of the SCM methodology. Terms of Reference for the local firms ${ }^{12}$ have been elaborated. Note that consultants building the inventory will require proper training before the start of the exercise, to

\footnotetext{
11 See Annex 2 for the information collection template.

12 See Annex 3 for an example of TORs for the elaboration of the inventory of licenses by local consultants.
} 
ensure that data will be captured consistently (if different people are involved) and in a way that is appropriate for SCM analysis.

For reference, a list of typical categories generally subject to licensing is available in Box 6 below. The results of the inventory should be cross-checked with this list to ensure that key areas of licensing have not been overlooked. Note that licensing generally occurs within these sectors but the extent of regulation and control will vary by type of license and by area.

\section{BOX 6 Typical Categories of Activities Subject to Licensing}

1. Environmental protection: control pollution and environmental hazards

2. Sensitive and hazardous substances: control over movement of and activities with radioactive substances, dual-use goods, precursors and other controlled substances

3. Agriculture and fishery, food safety: control of food supply chain, including sales of chemicals used in agriculture, farms, food processing establishments

4. Medicine and pharmaceutical activity: medical and veterinary establishments, manufacturing and trade-in medicines and other controlled substances; medical profession is controlled mostly in the form of regulation of professional activities of individuals and specialists by simply requiring graduation from a recognized educational establishment; or by requiring their ongoing accreditation with professional bodies, and receipt of certificates of competence from professional bodies

5. Security: control over movement of and activities with arms, ammunition, explosives, and so on, including control over establishment of private armed units security services

6. Banking and other financial market participants: licensing of banks (and to a different degree financial intermediaries and related service providers in different jurisdictions). Licensing is predominantly used to establish a system of regulation and control over deposit-taking institutions, "recognized banks," and "licensed deposit takers" to protect depositing public

7. Excise goods: activities related to manufacturing and trade in excise goods (tobacco, liquor, petroleum, precious metals and stones)

8. Transport services: commercial transport services by air, rail and sea, commercial transport by road as well as some related services, such as freight forwarders and possibly motor vehicle dealers

9. Construction: activity of construction service providers (in reformed countries construction service providers are no longer licensed; regulation that exists is mostly in the form of regulation of professional activities of individuals and specialists by requiring their accreditation with professional bodies, receipt of certificates of competence from professional bodies, and so on)

10. Education: in some jurisdictions, establishment of educational institutions (mostly though, observance of specific requirements for the content of programs under accreditation schemes) 


\section{Box 6 (continued)}

11. Provision of liberalized utility services: production, transmission, distribution and supply of thermal energy and electricity

12. Communication: provision of telecommunication services; broadcasting; postal services

13. Real estate: land surveyors and real estate valuators; sometimes agents

14. Customs: activities of service providers (customs brokers); control over premises presenting fiscal risks (duty-free trade, storage of goods without customs clearance)

15. Gambling and Lottery: operation of gambling establishments and organizing lotteries

16. Mining and resource extraction

17. Other (such as provision of employment services, certifying the means of measurement, operation of crematoria, sale of fireworks, and so on)

Source: Bureau of Industry Economics (1996)

A decision should also be taken whether the inventory should cover licenses, permits and authorizations administered at the subnational level ${ }^{13}$. This may be essential, in fact, as a substantial share of administrative burden faced by businesses may result from subnational licenses and fees. Including them in the inventory would make sense from a company's point of view, as businesses simply cannot legally operate without having obtained all the required licenses, regardless of the level at which they are administered. However, in most countries where provincial and municipal governments have the competency - whether de jure or de facto — to introduce new regulations, this task could be enormous if one aims to be exhaustive (especially if licenses differ from one municipality to the next!). In such cases, the costs and benefits of a comprehensive inventory at the subnational level would likely suggest selecting a manageable set of economic centers to provide a good picture of what the licensing situation and practices might be in other provinces and municipalities.

\subsection{Using the Standard Cost Model to Benchmark Compliance Burden}

Using the data gathered through the inventory, an estimation of compliance costs imposed on businesses by the licensing system can be calculated with the SCM methodology described in Box 7. Standard basic information can be entered in a "business costs calculator," which consists of one spreadsheet per license, in which each required step is detailed, with a simple framework to estimate the costs and time associated with each step, and cumulatively, for each license.

\footnotetext{
${ }^{13}$ Refer to section 3.5 below for more details on this.
} 


\section{BOX 7 Standard Cost Model}

The SCM is a method for measuring the administrative burdens imposed on businesses complying with various regulations and requirements ("information obligations," according to SCM terminology). The SCM was first introduced in the Netherlands in the 1990s, and has been further developed there and in other OECD countries.

The starting point of SCM analysis is the identification of information obligations. The SCM can measure information obligations arising from various sources, including all existing laws and regulations; a specific field of laws and regulations (such as fiscal rules, the transport sector, starting a business, or employing employees); or requirements imposed by a selected government body.

To determine the administrative burden, compliance costs relating to each "information obligation" are calculated, including fees, number of businesses subject to the requirement, and frequency of filings. The SCM is not an entirely quantitative measurement, as it relies on certain assumptions.

The SCM can be applied to the "stock" of all or selected regulations (those already in force), or the "flow" (proposed) regulation or legislation. The SCM can thus be a tool in the preparation of regulatory impact assessments. The SCM is also used as a catalyst for targeting reform efforts, as a baseline measure before reforms are underway, and as a tool to set quantitative reform targets and track reform progress.

Standard Terms of Reference ${ }^{14}$ have been developed for international consultants to complete this task, which complements the elaboration of the inventory highlighted in Section 2.3 above. Ideally the two exercises should be combined with both teams of consultants working together to ensure that the data gathered locally can be effectively used with the SCM. This generally requires some specific training of the data gathering team, which includes the local consultants and technical counterparts in the concerned regulatory agencies.

The original SCM methodology has been most successfully used in relatively data-rich and high-capacity countries. However, with certain analytical and methodological modifications, the SCM has proven to be a useful and relatively low-cost method for estimating administrative burdens in countries where data is incomplete and resource capacities are limited. The Investment Climate Advisory Services has been reviewing the application of the SCM in different client countries in the developing world, and the findings and lessons are presented in World Bank Group (forthcoming) Applying the Standard Cost Model in Developing and Transition Countries: Issues for Practitioners.

A complementary approach to measuring compliance costs ${ }^{15}$ relies on surveying a representative sample of firms. Measuring compliance costs has been piloted in a series of

\footnotetext{
${ }^{14}$ See Annex 4 for an example of TORs for the application of the Standard Cost Model to business licensing reforms.

${ }^{15}$ See Coolidge (2010)
} 
countries, ranging from Madagascar to Serbia. It can apply to both licensing and tax requirements. It aims to:

- estimate the overall burden (compliance costs and risks) of licensing, permits and inspections on the formal business community, including the costs of informal payments and the cost of hiring external assistance;

- document the range and distribution of experiences of businesses in those jurisdictions with the relevant procedures, including extreme delays; and

- create a baseline (after reforms have been enacted) against which one can estimate the relevant aggregate benefits, cost savings, and risk-reductions in those jurisdictions due to reform of licensing and permits.

In addition, the survey captures the actual experiences of firms, including common problems that are usually assumed away by the SCM, such as the time required and difficulties encountered by firms trying to understand the requirements, the tendency of bureaucrats to return application forms and demand additional documentation, and the practice of firms resorting to informal payments and "connections" to complete the procedures or to avoid delays. The survey targets a much larger and more representative sample of firms than is usually accommodated in the SCM. It is, however, more costly and requires more time to be carried out properly.

Another advantage of the survey approach is that it allows for targeting questionnaires to specific licenses that may have been identified as particularly important, thereby refining the diagnostic findings. As a complement to the SCM, it also provides a crosscheck of the information gathered in the inventory.

Project teams can find out more on the SCM methodology by taking an introductory course on the United Kingdom's Department for Business Enterprise and Regulatory Reforms (BERR) Web site ${ }^{16}$. The course provides a comprehensive introduction to the methodology, as well as its application to the reform process.

\subsection{Setting Quantitative Reform Targets}

A recent review of the Dutch Administrative Burden Reduction program ${ }^{17}$ finds that setting "the 25 percent target is the main success factor [of the program]. The 2003 baseline measurement of $€ 16$ billion administrative burdens is the most important factor behind the success of the Dutch reform program. The quantification and target allow for a transparent evaluation of progress and a way to track the performance of individual ministries."

\footnotetext{
${ }^{16}$ See www.scmtraining.berr.gov.uk.

17 See World Bank Group (2007), page 6. The Dutch Administrative Burden Reduction program is one of the most innovative initiatives in cutting red tape, and its model has been followed by several other countries.
} 
The cost reduction target is set against the baseline measurement of administrative costs imposed on businesses (see Box 8), which is commonly calculated using the SCM methodology ${ }^{18}$. Other methods can be envisioned, such as the use of time-and-motion studies on standard businesses and the introduction of business surveys to measure annoyance costs and target the reforms.

\section{Box 8 Determining the Appropriate Burden Reduction Target}

Because measures of administrative burden are estimates (a lot of assumptions go into SCM calculations) and the "ideal" licensing system cannot be foreseen before the reform, it is not possible to set the target on the basis of a strict scientific approximation of feasible reductions.

In many cases, the burden reduction target can be determined on the basis of comparison with other countries that have gone through similar reforms. A number of leading OECD countries $^{20}$ with seemingly more efficient regulatory practices than many developing countries have set and implemented burden reductions in the order of 25 percent. This is also true in a number of African countries, where reforms are underway ${ }^{21}$.

The target gives regulatory agencies an objective of reducing the administrative costs imposed on businesses by the licenses they administer. The target should be set agencyby-agency with no a priori exemptions, and to be achieved within a set timeframe. The cross-ministerial reform committee should work with regulatory agencies in helping them identify cost reduction measures (such as simplification of procedures, elimination of documentation requirements, and reduction of the amount of fees).

\subsection{Establishing a Reform Committee with Explicit Mandate}

A reform committee should be established, with an explicit political mandate to drive the licensing reform process. It is generally critical for this mandate to be very strong, if possible enacted by decree from the top of government (such as Presidency or Prime Minister's office) to encourage full participation in the process by line ministries and regulatory agencies.

The chairperson of the reform committee is also key to a successful reform. Suitable candidates should be identified and detailed Terms of Reference ${ }^{19}$ can be drafted along the lines outlined in Box 9 below. The amount of work and the remuneration should be determined. The chair should have a sound knowledge of law and economics, including regulatory reforms. He or she should be effective, efficient, and reform-minded. Prior

\footnotetext{
${ }^{18}$ Refer to Section 2.4 for more details on the Standard Cost Model.

19 This includes The Netherlands, Denmark, and the Czech Republic.

${ }^{20}$ This includes Burkina Faso, Kenya, Madagascar, Rwanda, and Zambia.

${ }^{21}$ See Annex 5 for an example of Terms of Reference for the Chairperson of the Reform Committee.
} 


\section{BOX 9 Typical Responsibilities of the Chairperson}

- Leads the reform committee in completing the action plan within the budget

- Coordinates with the Ministry of Justice and meets with the ministries as needed to ensure that ministries comply with the decree on streamlining the regulatory environment for business activities

- Ensures preparation of documents needed to launch the review process (instructions, templates and other materials)

- Drafts decisions, explanations, and legal amendments for each license as required

- Estimates budgetary impacts of the proposed reforms

- Consults with business representatives and ensures transparency of the process

- Communicates with regulators during the review process

- Supports final discussion and appeals in Ministry of Economy, Ministry of Finance and others

- Revises final recommendations to reflect final consultations

experience shows that the chair should be influential within the country's legal system to fulfill the tasks.

The core task of the members of the reform committee is the review of licenses. This task consists of assessing the legality, necessity, and appropriateness of licenses and packaging this assessment into the final recommendations. Before the assessment, workshops, hearings, interviews and seminars may be necessary to come to a conclusion.

Although conceptually licensing reforms could be implemented through a different kind of institutional setup (such as the President's or Prime Minister's office), or selected key reform-minded ministries (for example, Economy and Finance), there are few practical examples of successful comprehensive reforms driven that way. Experience suggests that the reform committee should be cross-governmental (including the main ministries interested and affected by the reforms), and ideally of a public-private nature.

\subsection{Validating Inventory Findings with Owning Agencies and the Private Sector}

Validation workshops should be organized with the private sector and regulatory agencies, with the objective of confirming the findings of the inventory, including:

- Does the inventory capture the complete list of operating licenses?

- Do the calculations and estimations of costs associated with each license reflect the reality faced by business operators?

- Does each license constitute a reform priority for each sector? 


\section{BOX 10 Three Dimensions for Choosing Reform Committee Members}

\section{Should members come from the public sector exclusively, or include the private sector?}

- In principle, there have been good experiences with civil servants only, using frequent and tailored working sessions with key private sector operators.

- The rationale for a heavy public sector representation is that conducting licensing reforms requires an insider's understanding of business regulations, procedures, and functions of regulatory agencies. Additionally, reforms will be implemented by the concerned regulatory agencies, and having their staff as part of the process early on is a good way to ensure proper implementation.

\section{Which ministries and agencies should be represented?}

- In principle, the main ministries and agencies that have the authority to elaborate, review, or approve business licensing regulations should have a delegate in the reform committee. At a minimum, this means the Ministry of Finance, the Ministry of Trade and Industry, and sectoral ministries with a substantial mandate of business activity such as agriculture, tourism, mining, and so on.

- Other entities directly linked to legal or regulatory reforms (for instance, the legal committee at the attorney general's office) should be involved, if indirectly.

- The reform committee's mandate is technical (that is, reviewing all licenses according to a set of qualitative criteria). Members of the committee should be chosen for their technical expertise on licensing procedures.

- Importantly, the majority of the reform committee should be pro-reform, which can often be ensured by a more numerous representation of finance, trade and industry.

\section{What is the profile of members?}

- In principle, members should be sufficiently senior in their ministries and have enough power and influence in their ministries to push reform implementation forward. At the same time, they need to have a solid technical understanding of the licensing regulations, procedures, and administration so they can propose streamlining measures. Finally, they need to have sufficient dedicated time away from their day-to-day work.

- Typically, this means mid- and high-level civil servants still involved in the technical work, with substantial years in their ministries, but not department directors in timeconsuming management positions.

The goal is to finalize the inventory and generate consensus on the calculations and estimates made for each license, so that a baseline that is credible and acceptable to the various stakeholders can be established for the reform. Opening the inventory to all stakeholders for criticism and comments is also useful, in that it demonstrates transparency of process and openness of the reform committee to different opinions.

Workshop minutes for each validation workshop should be produced, documenting key issues, decisions, names and organization of people attending, and other relevant 
information. The key purpose of the minutes is to document which consensus was reached and by whom. The minutes will be shared with participants after the workshops and endorsed by them as representative of the discussions and outcomes.

\subsection{Identifying Quick Wins to Spur Reform Momentum}

The initial inventory should allow for the identification of a set of licenses that may be relatively easy to reform or abolish. The objectives of identifying and delivering "quick wins" right after the central diagnostic piece is completed are: (a) to show rapid results to clients, as well as other stakeholders (internal and external); (b) to spur reform momentum and appetite for more longhaul reforms; and (c) test the reform setup — the reform committee, in particular — and its resolve and capacity to deliver reforms.

Key criteria used to identify potential quick wins:

- Technically easy to fix: streamlining or elimination should require only an executive decision (by minister or head of department), rather than parliamentary approval or other form of consultation.

- Not controversial: the changes proposed should generally lead to an easy consensus between the administration and other stakeholders. Contentious issues should be kept for the broader reform effort, as they will require time spent in consultation and possibly negotiation.

- Impact on Doing Business indicators: improvement in Doing Business indicators can be a powerful way to strengthen appetite and support for reform, given the visibility of the report. It is worth checking whether some rapid improvements can be made, especially on the indicators for "starting a business" and "dealing with construction permits."

Typically, licenses that are redundant, obsolete, not enforced or complied with, and have little impact on legitimate regulatory objectives, should be considered for elimination. They pose a regulatory risk to operators, and should not be controversial to remove. But quick wins can also include some other measures that improve the business licensing environment, such as making forms and information publicly available and improving the client interface at key regulatory agencies.

Quick wins differ from "high-priority" licenses ${ }^{22}$. The former, as mentioned, can be marginal licenses that do not have a lot of impact on private enterprise. Priority licenses, however, are of strategic importance and generally affect a high number of businesses.

22 See section 2.9 
Reforming them could have an important impact on the private sector. However, reforms of priority licenses are likely to be either controversial or technically complex, and would therefore be best addressed within the framework of the broad-based licensing reform effort.

The proposed quick wins should be validated by the private sector through workshops, where licensing agencies and users can share views on how to improve the system. Workshops should be organized along thematic lines and led by the reform team. Concrete quick-win proposals prepared by the team should be used as a starting point for discussion. Agreed reform actions should be recorded in a document that can serve as minutes of the outcomes of the workshops and which focuses on implementation.

A quick-wins report should be elaborated and submitted by the reform committee to the government for approval. The report needs to carefully articulate how these early results fit in the broader picture of licensing reform, which will address priority licenses as well as more systemic issues.

Once implemented, improvements should be widely publicized, thus helping raise awareness and gain support for reform. This will help address clients' need to show timely results to their constituencies.

\subsection{Selecting High Priority Licenses ${ }^{23}$}

Measuring total compliance costs can be expensive and time consuming. It may not be practical or desirable to measure all existing licensing regulations in a very detailed fashion $^{24}$. However, an in-depth analysis of a specific set of licenses that businesses say are the most burdensome is important, in order to make sure that the project delivers highimpact reforms.

Such licenses are generally referred to as "high priority," and usually feature the following characteristics:

- Significant license. The license impacts a relatively large number of businesses, or it has a medium or high impact on those businesses affected by the license (check with the regulatory agency on how many licenses were issued in previous years).

- High complexity. The procedures are long and complex, various agencies are involved, and documentation requirements are heavy.

\footnotetext{
${ }^{23}$ This section draws heavily upon World Bank Group (2007).

${ }^{24}$ The Standard Cost Model allows for general assumptions to be made to estimate costs across the licensing system as whole, by, for instance generalizing procedures into standardized steps. This provides a cost-efficient way of estimating overall compliance costs.
} 
- Strategic industry. These are generally licenses regulating an industry that plays an important role in the national economy (check shares of gross domestic product by industry and the government's growth strategy for priority sectors).

- Cross-cutting license. Some priority licenses are not sector-specific, but of a cross-cutting nature, in that most businesses will be affected by them. Traditional candidates include environmental, zoning, safety-at-work, and building regulations.

High priority licenses can be identified through consultations with the private sector, whether through business surveys or consultation groups. This can typically take place at the same time as validation workshops (see section 2.7). Business input can also be used to identify "business-as-usual-costs," which should not be subject to reduction targets.

The detailed burden measurement should focus on direct costs, such as costs of capital, operating, paperwork and time incurred in complying with regulations. While useful for the political debate, the quantification of risks and benefits should only be used on a select basis, where the debate is heated or where data is more readily available.

\subsection{Initial Drafting of a Medium-Term Regulatory Reform Strategy}

Licensing is only one aspect of business regulations. While reforming the licensing regime will help relieve businesses of substantial administrative burdens, more can be achieved through a reform of other business regulations. Building upon experiences from licensing reform as it unfolds, a strategy for broader regulatory reform should be elaborated, and the scope of reforms should be taken beyond the licensing regime. In various projects, the successes of licensing reform have triggered a widely shared appetite for reforms in a powerful way, thus enabling the government to deepen the reform agenda.

This broader regulatory reform strategy ${ }^{25}$ should be drafted early on, to outline a general direction for the reforms that is consistent with and complementary to the ongoing licensing reforms. The strategy should then closely follow the implementation of licensing reform and build on its achievements, such as the establishment of an e-registry ${ }^{26}$, for instance. Potential focus areas for a broader reform strategy can be found in the government's growth and poverty reduction strategies. The reform strategy could involve expanding on regulatory issues prioritized in previous diagnostics but not addressed by the licensing reform. The strategy could also include capacity-building measures for the public and private operators.

\footnotetext{
${ }^{25}$ See Chapter 5 for more on broadening the scope of reform beyond the licensing system.

${ }^{26}$ See section 4.3 for more on e-registries.
} 


\section{Box 11 Why a Medium-term Regulatory Reform Strategy?}

Reform of business regulation is notoriously difficult. Vested interests in the public and private sectors, fears of the consequences of change, and the complexity and uncertainty of reform in dynamic economic and social environments make successful regulatory reform a rare commodity. Isolated and one-time reforms usually do not produce concrete, lasting benefits for the private sector. Reforms aimed at single processes and rules will never catch up with the productive capacities and incentives of governments to create regulations and controls. The issue is clearly a systemic one.

Some governments do meaningfully reform, and have reaped the fruits of success. Countries that have succeeded in managing a broad reform program over several years - even over several governments - have shown the fastest transitions and the greatest gains in economic development. A medium-term reform strategy sustains the reform, provides a focus and rallying point for reform, and provides a basis for monitoring the reform progress. ${ }^{27}$

The objective of a regulatory reform strategy is to define clear and operational targets for the improvement of the regulatory business environment and to establish the institutions and processes required to implement the strategy in an efficient, transparent and accountable manner. A regulatory reform strategy must focus on organizing, prioritizing and ensuring the implementation of well-identified major regulatory problems.

A consolidated and focused regulatory reform strategy or program is not in any way a guarantee for successful reform. However, international experience suggests that successful reforms are often started with a clear and well-designed medium-term reform strategy that has room to evolve over time. Such a strategy and its components must be an integral part of the country's private sector development strategy, and should also be coordinated with programs for governance reform, public sector reforms, and anti-corruption.

To make a preliminary assessment of the quality of the regulatory framework, the following checklist in Box 12 developed by the OECD and several national governments may be used. It should help identify areas where the design of the regulatory framework is deficient and requires further improvement.

Broader regulatory reforms are likely to encompass business inspections as well, and therefore should be considered within the framework of a medium-term regulatory reform strategy. After all, licensing and inspections constitute the two faces of a same coin. Regulations and inspections to enforce them are central instruments in the government's toolbox to protect public interests. Both need to meet regulatory quality standards to ensure a sound business environment.

IFC (2006b) examines good practices of effective business inspections, and Coolidge (2006) offers models for inspections reform that reduce the compliance burden and enhance standards.

\footnotetext{
${ }^{27}$ World Bank Group (2009), Lessons for Reformers: How To Launch, Implement, and Sustain Regulatory Reform. An Analysis of Six Case Studies In Developing and High-Income Countries.
} 


\section{BOX 12 Features of Good Regulatory Administration and Practices}

\section{Governance of the regulator}

- Managing risks, including identifying, prioritizing and mitigating risks affecting both the effectiveness of the regulator and the compliance of business with regulations

- Accountable decision-making, persons delegated regulatory powers have a clearly defined role, are accountable, and are guided by clear policies and procedures

- Managing performance, including effective management and communication

- Managing probity, effective mechanisms to minimize corruption or misconduct

\section{Information management}

- Clear guidance on what data should be stored and how it should be stored

- Systems ensure appropriate data captured, stored, used properly, and protected

\section{Relationship management}

- Communication with stakeholders is open, transparent, responsive, and cost effective

- Complaints and appeals are managed quickly, effectively, and transparently

- Relationship outcomes (often defined in service charters and codes of conduct) are measured and reported on in a transparent manner

\section{Resourcing issues}

- Regulators rarely have all the resources required to meet stakeholder expectations so resources should be allocated effectively and efficiently to high priority risks

- Cost recovery through fees and charges should only be applied where businesses benefit directly from regulations and should only transparently recover direct costs

- Fees and charges should be avoided where the regulations generate significant community benefits or generate other risks and costs (that is, cross-subsidization or corruption)

\section{Receiving applications and monitoring compliance}

- Regulators should have effective, efficient, and transparent processes for receiving applications from businesses, assessing compliance, and making decisions

- The compliance monitoring should include a clear, documented strategy; risk-based work program; and timely, evidence-based and objective compliance processes

- Requirements should be easily accessible and understood by businesses, and communicated in an effective and timely manner

- Monitoring and compliance strategies should minimize unnecessary burdens

\section{Addressing non-compliance}

- Response to non-compliance should be commensurate with the risks generated by noncompliance and the compliance history of the business

- Regulators' response should be timely, proportionate, lawful, and properly documented

- A clear plan is in place to manage and assist the return of the business to compliance 
Box 12 (continued)

\section{Responding to adverse events which may cause harm}

- Regulators should try to ensure that they are aware of adverse events when they occur, are ready to respond where appropriate, and have the ability to review processes to respond to any lessons learned

Sources: OECD (1995), OECD (2002), Australian National Audit Office (2007)

\subsection{Identifying a Strategy for Legal Implementation of Reforms}

Streamlining the licensing system will require change in existing legal instruments, which will have been identified in the course of the inventory. This can vary substantially from one country to the next, depending on legal tradition and historical development. In any case, a legal strategy should outline early on the most effective way of ensuring legal implementation of reforms.

When reformers plan their legal strategies for adopting and implementing licensing legislation, they should consider bundling the licensing-related reform bills and including them in the annual budgeting process.

As discussed in the Policy Framework Paper on Business Licensing Reform and Simplification $^{28}$, the advantages of bundling are based on the premise that vested interests (which may lose out from the licensing reforms) will have a more difficult time successfully mobilizing resistance when the reforms are presented in a single, comprehensive package. In contrast, gradual one-by-one implementation through a series of revisions of specific acts and regulations would give vested interests better time and focus to mobilize resistance. Bundling may happen at several occasions, the most important one when Cabinet approves recommendations for comprehensive licensing reform. Ideally the reform champion should put the package forward as "take it or leave it."

After this, legal implementation may happen through executive orders of various kinds, and through Act(s) of Parliament. For the latter, a good solution is through an "omnibus" bill (that is, as a Business Licensing Repeals and Amendments Act), rather than a long series of individual revisions to specific parent acts for the reasons noted above. The bundling approach may strengthen the likelihood of implementation of the licensing reforms, since implementing instructions can be disseminated at once and systematically to regulators and other government bodies.

\footnotetext{
${ }^{28}$ See World Bank Group (2010).
} 
The advantages of including licensing reforms in the annual budgeting process are based on the premise that governments most often have a constitutional obligation (and other good reasons) to pass the budget by a certain date. It is a widely recognized practice for a range of policy measures with state budgetary implications to be passed as part of the passing of the broader budget process. In other words, if the licensing reform can become part of policy measures implemented within the budget, there is a good chance that it will pass with the budget and by a specific deadline. Furthermore, it is unlikely that the parliament will block a finance bill because of a licensing reform. The budgeting approach may also strengthen the likelihood of implementation of the licensing reforms, since government will follow up and there are established measures to ensure compliance.

It is important to note that the above methods can and must comply with good governance principles, such as transparency and consultations with affected parties. In fact, consultations can still take place at the various key stages of policy formulation, such as initial consideration of comprehensive licensing reforms, drafting, and revisions.

\subsection{Designing a Monitoring and Evaluation Framework}

It is essential to establish a robust monitoring and evaluation (M\&E) system early on in the project in order to agree on targets, track progress, and demonstrate success. However, applying M\&E to licensing can be both complex and challenging. Typically, as with other regulatory and investment climate reforms, outcomes and impacts can be difficult to measure, and attribution is often problematic.

Project teams should refer to IFC, GTZ, and DFID (2008), the handbook of monitoring and evaluation for investment climate reforms, which provides general guidance and practical tools to design and implement an M\&E plan. This step focuses on identifying the appropriate indicators and targets. These should be agreed upon with the clients, and leverage available data as much as possible.

Also note that IFC has identified a set of indicators applicable to business licensing reforms (Box 13). Contextualizing these indicators is essential in tailoring their use to specific projects. Indeed, when tracking reforms or providing proof of documentation, the corresponding components and activities will provide the context that is not captured by the indicators themselves.

A number of other supplementary indicators may be used, depending on the project design and the agreed targets with the government. The list in Box 13 does not supplant any other project-relevant indicators. However, to ensure comparability of results across countries, the use of standard indicators is encouraged whenever possible. 


\section{BOX 13 Using Monitoring and Evaluation Indicators in Business Licensing Projects}

The following are standard types of M\&E indicators that can be used to measure progress in achieving reform:

\section{Outputs}

- Number of entities receiving advisory services

- Number of reports (assessments, surveys, manuals) completed

- Number of new laws, regulations, amendments and codes drafted or contributed to the drafting

- Number of procedures, policies and practices recommended for improvement or elimination

- Number of media appearances

- Number of participants in workshops, training sessions, seminars, conferences, and other events

- Number of women participants in workshops, training sessions, seminars, conferences, and other events

- Number of participants reporting satisfied or very satisfied with workshops, training sessions, seminars, conferences, and other events

\section{Outcomes}

- Number of recommended laws, regulations, amendments and codes enacted

- Number of recommended procedures, policies and practices that were improved or eliminated

- Average number of days to comply with business regulation

- Average official cost to comply with business regulation

- Number of entities that implemented recommended changes

- Number of businesses completing a new or reformed procedure in a given jurisdiction

\section{Impacts}

- Value of aggregate private sector savings from recommended changes (US\$)

- Number of formal jobs

Source: IFC Advisory Service M\&E intranet website. See IFC (2008b) Standard Core and Supplemental Indicators for Business Enabling Environment Projects for detailed definitions of each indicator

Elaborating a specific and well-considered logical framework is the first step in developing a meaningful M\&E plan. Ideally the M\&E framework should be an extension of the projects log frame and vice-versa. When it is done upfront, it makes the M\&E easier to plan and execute. In addition, it makes it easier to tailor standard indicators to the project.

Finally, an essential step in measuring results resides in establishing a good baseline before reform implementation starts. However, as discussed in Box 14, this can be a challenging task in data-poor environments. 


\section{Box 14 How to Get Baseline Data When None Is Readily Available}

In many developing countries, the availability of data that can serve as baseline for the project's M\&E framework ${ }^{29}$ is very limited. When data is missing on the number of licenses available and the costs and time they impose on businesses, a set of tools can be used to estimate it.

The Standard Cost Model methodology can help measure administrative costs and burdens on business resulting from a license or group of licenses. By estimating the time and costs involved in complying with licensing requirements, the SCM can help:

- establish a baseline against which successes of the reform can be measured;

- identify licenses that play a particularly important role in the economy; and

- identify the main bottlenecks in the licensing system.

Compliance Cost Surveys provide a complementary approach to the SCM, in terms of establishing a baseline. One advantage of the survey approach is that it allows for targeting questionnaires to specific licenses that may have been identified as particularly important, thereby refining the diagnostic findings, as well as tracking results.

${ }^{29}$ See section 2.4 for more on the Standard Cost Model and Compliance Cost Surveys. 


\section{Chapter 3: Review of the Licenses}

This stage constitutes the bulk of the actual reform work: where identified licenses are reviewed and recommendations for each of them are made, through memos prepared by the reform committee to be approved by the government. This should result in a decision to keep, eliminate, or streamline each individual license, with identified means to implement that decision.

This process will be labor-intensive for the reform committee, as well as for the regulatory agencies that will be actively involved in the review of the licenses they administer. Managing information flows will often be challenging, and therefore careful attention should be dedicated to establishing effective communication mechanisms, including a database to store the feedback and information provided by the regulatory agencies.

\subsection{Designing a License Information Database}

The reform committee will manage information flows with licensing authorities. An infrastructure must be set up to file and retrieve the answers to the questionnaire. Some of the key questions to consider in this step include:

- What kind of database is needed?

- Who should have access?

- Who updates and maintains the data?

- How will the follow up on incomplete, ambiguous, or lack of responses be organized?

At its most basic, a spreadsheet reflecting the questions asked in the template during the information-gathering exercise could be used, with one line for each license and answers to questions detailed in the columns. 


\subsection{Engaging with Regulatory Agencies in Making Reform Proposals}

The reform committee should work to build an effective dialogue with the concerned regulating agencies. The objective is to have regulators fully involved in the reform process, proactively making reform proposals. To trigger this dynamic, the committee should issue letters of request, which ask for the agencies' cooperation in confirming inventory findings about the licenses they administer, and informing them of the reform process and targets. The letter should request their responses by a set deadline and be accompanied by the government's decree, which shows strong political commitment to ensure maximum responsiveness from the authorities.

There should be credible sanctions for non-compliance, based on the principle of "reversal of burden of proof" described in Box 15. However, note that there are alternatives to the dogmatic application of this principle, and variations depending on the country. Members of the reform committee should be available to provide further detailed information and explanations regarding the request.

\section{BOX 15 The "Reversal of the Burden of Proof" Principle}

Central to the top-down approach to business licensing reforms is the principle of "reversal of the burden of proof." This establishes a mechanism to ensure the active participation of regulating agencies in the reform.

In its most dogmatic form, the "reversal" implies that regulators, who are the "owners" of the reviewed licenses, are obliged to prove that the concerned licenses match pre-defined criteria of regulatory quality. Should the regulators fail to notify the government of their existence or justify their licenses past a set deadline, the licenses would be eliminated by default. This mechanism reverses the incentives of otherwise reluctant regulators to share data and information about "their" licenses. All surviving licenses would then generally be listed in a centralized electronic registry.

However, it is not always possible or desirable to implement licensing reforms in such a dogmatic way: countries may face constitutional, legislative, or political constraints in eliminating licensing laws or regulations by default. In fact, most countries that have implemented top-down, comprehensive licensing reforms have done so using a lighter, more flexible approach to involving regulators in the reform. Setting quantitative burden reduction targets ${ }^{30}$ to be achieved by each regulatory agency has proven to be a key element of success in several countries.

Box 16 provides an example of the reform architecture for Madagascar. In this setting, the reform committee is made up of a group of technical experts, who work with the regulatory agencies to identify and propose burden-reduction measures. These measures are endorsed by the board of a cross-ministerial agency — the Economic Development Board of Madagascar (EDBM) - which has the mandate to attract investment and improve the

\footnotetext{
${ }^{30}$ See section 2.5 for more on quantitative target setting.
} 


\section{Box 16 Reform Architecture in Madagascar}

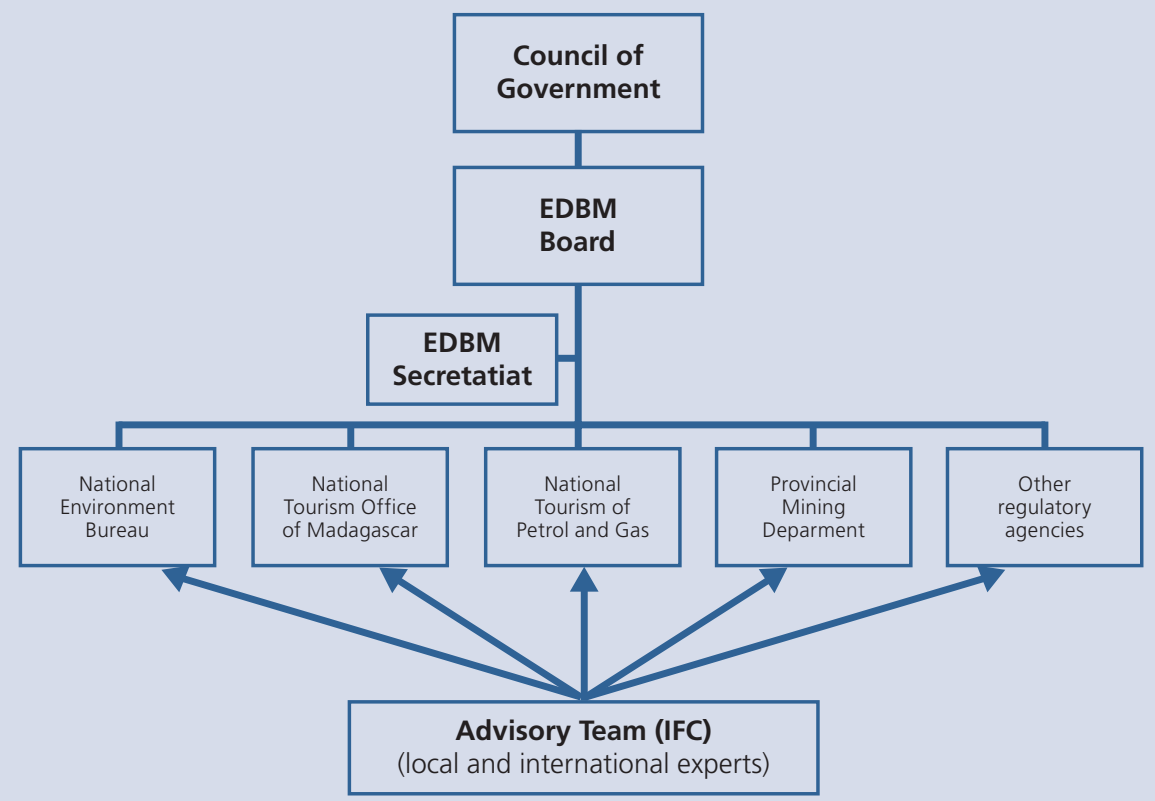

Source: Business Licensing Reform in Madagascar, a joint EDBM/IFC project.

country's business environment. The EDBM submits these burden reduction measures as a package for approval by the Council of Government.

\subsection{Review of Licenses by the Reform Committee}

This step is at the core of the licensing reform, whereby the technical experts of the reform committee review all identified licenses against an established set of criteria detailed below. This is the most labor-intensive part for the chair and members of the reform committee.

The review criteria provide a basis for the committee to assess whether the license places a fair burden on businesses or should be simplified or eliminated. During the review process, the committee should address the following questions:

- Is the license legal? Is there a clear and sufficient legal basis for the license? If the answer to this question is no, the license should be eliminated.

- Is the license necessary? Necessity is defined as the need to have in place ex-ante regulation in the form of a license for health, safety or environmental reasons. If the answer to this question is no, the license should be eliminated, 
unless other politically sanctioned rationales prevail. Economic regulation in general should not be implemented through ex-ante regulation such as licensing, but through regulation enforced ex-post the commencement of business activities. Unnecessary licenses include, for example, those used for revenue collection exclusively, or that duplicate other regulatory tools set up to ensure compliance.

- Is the license efficient and business friendly? In most cases licenses can be further streamlined. If the answer to the question is yes, the reviewer should consider the following options for streamlining:

- Conversion of license to notification

- Apply "silence is consent" (that is, authorization considered granted if the regulatory agency has not notified the applicant within a pre-defined timeframe)

- Should thresholds be amended (for example, change the number or type of businesses and occupations affected by the license or permit)?

- Change reporting frequency and renewal frequency

- Amalgamate with other license or permit

- Reduce information requirements and focus only on those required to administer the license or permit

- Could processes for receiving and assessing license applications be simplified and made quicker (for instance, deadlines for issuing licenses)?

- Are there appeals processes and could they be made more independent, effective, transparent and effective?

- Could inspections be improved, by focusing more on high risk businesses, increasing transparency and predictability (such as using checklists or similar measures)?

- Can access to licensing requirements be improved (through an electronic registry?), providing information and allowing forms to be lodged electronically?

- Can the decision criteria for each license or permit be made publicly available?

- Can similar licenses and permits issued in other jurisdictions be recognized as being valid in your jurisdiction (via mutual recognition or similar measures)?

- Can fees and charges be modified?

A detailed checklist with the key features of good regulations can be used to guide the review of the business licenses. Each regulatory instrument should feature the aspects described in Box 17 below.

In the course of the review, workshops, seminars, or hearings might be set up to address unclear or sensitive matters. In Kenya, for example, the reform committee often consulted with the private sector to set priorities, which ensured the greatest impact on the investment 


\section{Box 17 Checklist of Key Features of Good Regulatory Design}

\section{Minimum needed to achieve objectives:}

- benefits greater than the costs

- avoids unnecessary restrictions

- focuses on the problem

- does not impose unnecessary burdens

- does not restrict competition unless demonstrated net benefit

\section{Not unduly prescriptive:}

- performance and outcomes focused

- general rather than overly specific

\section{Accessible, transparent and accountable:}

- readily available to the public and business

- easy to understand

- fairly and consistently enforced

- flexible enough to deal with special circumstances

- open to transparent, and where appropriate, independent appeal and review

\section{Integrated and consistent with other laws and regulations:}

- addresses a problem not addressed by other regulations

- recognizes existing regulations and international obligations

\section{Communicated effectively:}

- written in clear and concise language

\section{Mindful of compliance burden imposed:}

- proportionate to the problem

- set at a level which avoids unnecessary costs

\section{Enforceable:}

- provides minimum effective incentives for reasonable compliance

- able to be monitored and policed effectively

Source: OECD (1995), OECD (2002), Argy and Johnson (2003)

climate. These consultations were in many instances organized as public-private sector consultative forums in which tentative decisions were discussed openly. The committee had prepared reports on each consultative forum, which were distributed to the participants and other public bodies. It is important that such forums be well organized and publicized, and 
that delegates be given an opportunity to contribute freely. Experts can be invited to help lead the discussions and also to explain controversies.

\subsection{Paying Specific Attention to Sectoral Reviews}

In cases where certain sectors are particularly complex or strategic for the economy, project teams may need to rely on sectoral experts to help refine the analysis and review the licenses. As noted throughout this handbook, the approach proposed here highlights the advantages of tackling licensing reforms in a comprehensive way, rather than focusing on one or selected industries in particular. More attention could nevertheless be warranted within such a comprehensive framework to complement the expertise of the project teams.

To support sectoral reviews, the World Bank Group has produced a set of sectoral notes that analyze business regulations in a few key industries (including tourism ${ }^{31}$, mining ${ }^{32}$, and construction permits) ${ }^{33}$. These sectoral papers are based on case studies and aim to provide principles as well as examples of good and bad licensing practices.

\subsection{Rationalizing the System of Local Regulations, Fees and Taxes}

Licensing sometimes involves regulators imposing fees or charges to issue, administer and revalidate licenses. Box 18 below articulates the general principles that should guide the imposition of such fees and charges by regulatory agencies. Good practices regarding licensing and revenue-raising generally suggest that licensing should not be used as a vehicle to raise revenue because it is an inefficient mechanism, and because it imposes great uncertainty on regulated businesses. As highlighted in the Framework Paper on Business Licensing Reform and Simplification ${ }^{34}$, licenses primarily serve regulatory objectives to protect safety, health, the environment and other public interests.

However, in practice, the inappropriate use of licensing fees and charges as revenuegenerating instruments, or quasi-taxes, has been observed in many countries. The proliferation of such quasi-taxes tends to be an issue particularly (but not exclusively) at the subnational level, given the trend towards decentralization, whereby subnational governments are expected to deliver an ever wider range of services. They are not always granted the fiscal resources they need to finance these local public services, and must therefore rely on other, "parafiscal" sources. This term is inspired by the French word "parafiscalité,"

\footnotetext{
31 See World Bank Group (forthcoming). "Licensing Case Studies: Tourism Sector."

32 See World Bank Group (forthcoming). "Licensing Case Studies: Mining Sector."

33 See Moullier (2009).

34 See World Bank Group (forthcoming). "Policy Framework for Business Licensing Reform and Simplification."
} 


\section{BOX 18 Principles for Imposition of Licensing Fees and Charges}

The transparent imposition by the licensing regulator of fees and charges for licenses can be appropriate:

- on a cost recovery basis, where licenses generate direct benefits for the business receiving the license, such as a license accreditation resulting in business being able to charge higher prices; and

- where businesses generate negative effects of the broader community, such as pollution.

However, where licenses generate broader benefits for the community (such as enhanced health, safety or security outcomes), imposing licensing fees and charges will be inappropriate and inflict a wide range of costs on the community. Indeed, in such cases license fees and charges essentially impose a "tax" on services provided by business that benefit the broader community.

Where there is a broader policy objective such as improving health, safety, or security, license fees and charges can be applied in the short term where:

- revenue collected generates identifiable health, safety or security benefits for the community that clearly exceed the direct and indirect costs on businesses and the community in collecting license fees and charges; and

- licensing revenues are collected more effectively and at lower cost than broader taxation measures.

However, in practice these conditions are unlikely to be met, especially where there is a functioning broadly based taxation system in place. Indeed, in this situation the taxation system should be strengthened so that inefficient and costly licensing fees and charges can be reduced over time and replaced by more efficient revenue mechanisms, such as strengthened intergovernmental transfers or an appropriate local business tax.

which encompasses the revenue sources of line ministries, state agencies, and subnational entities, which do not flow in the Treasury accounts.

The use of licensing fees as fiscal instruments has practical implications for licensing reforms. Indeed, the elimination of such licenses, or reduction of the fees and charges associated with them, will have an impact on the revenue-raising capacity of the concerned local governments and regulatory agencies. This could seriously damage their ability to deliver essential public services. Additionally, government entities whose revenue base would be eroded by the reforms are likely to strongly oppose change, sometimes for valid reasons. It is therefore important for reformers to ensure that the removal of inefficient licensing or revenue-raising practices is complemented with efforts to compensate the local governments and improve revenue collection mechanisms.

The reform committee would need to provide options, maybe with outside assistance, to make up for these losses. Ideally, this would be done in conjunction with tax reform, through the simplification of the regime. These activities would imply close cooperation with other 
reform work on taxation, and the relevant government bodies (such as the Ministry of Finance, the Ministry of Local Administration, and provincial and municipal governments).

A recent short paper ${ }^{35}$ explores this topic in more depth, and provides an approach to dealing with this issue, including an overview of potential efficient revenue sources for local governments.

In the Balkans, IFC has partnered with subnational governments in applying the SCM to local regulations in Bosnia and Herzegovina, Montenegro and Serbia. This approach follows a similar model as the one introduced in this handbook for national regulations. Please refer to Thomas, Cordova-Novion, Batic (2009) for more on the Western Balkans model and experience.

\subsection{Preparing Decision Memos for Government Approval}

Standardized decision memos should be prepared for each license. A template ${ }^{36}$ has been elaborated for that purpose. Key information about each license, as well as the assessment made by the committee to eliminate, streamline, or maintain the license, will be summarized in these memos. Reform committee members must ensure that they take into account the inputs provided by the public and private sectors in the course of previous consultative forums.

The final report of the review will show which licenses will be abolished, streamlined, or kept without changes. The final report will be subject to a validation workshop with public and private sector representatives. After discussions and the submission of written comments, the reform committee will revise the final report to include valid inputs. In Kenya, the final report included decision memos, a list of licenses issued, a list of consultations made, and other relevant details. The committee will submit the final report (including all revisions) to the government for approval.

\subsection{Political and Communications Strategy to Support Adoption of Reform}

This is a cross-cutting step that must take place throughout the project. Building support for the reform starts before legal implementation. Depending on the implementation mechanism adopted, a political and communications strategy is needed to ensure that

\footnotetext{
35 See Corthay (2009).

36 See Annex 6 for an example of the type of information required in a Decision Memo.
} 
the relevant authorities (such as Parliament, ministries and other stakeholders) are fully briefed on and endorse the reform proposal.

In that context, the use of press and other media may prove crucial to securing a sufficient support base. Please refer to section 1.6 for more on using communications to support the reform process. 



\section{Chapter 4: Reform of the Licensing System}

In this stage, once a decision has been reached for each of the licenses, the changes must be implemented through the law and other types of regulation. The legal basis for each license will have been identified early on (in the inventory), and it will now be time to draft (or redraft) these pieces of licensing legislation, subject to the approval of the relevant legislative bodies.

But legal changes are not the end of the story. For actual reforms to be effective on the ground, they must be felt by businesses. To achieve this objective, this stage will also seek to build regulators' capacity to administer reformed licenses. Also, in order to inform users and enhance legal security, an electronic registry containing all valid (and reformed) licenses will be established.

\subsection{Legal Implementation of Decisions}

After a final decision is issued based on the recommendations of the reform committee, the legal implementation must be completed. Whenever possible, it is recommended that all necessary legislative changes be adopted in one package. This is the fastest and best way of defusing potential interference from well-informed special interests, and it ensures the licensing reform is comprehensive.

The best-suited legal implementation mechanism will have been identified previously ${ }^{37}$. The type of legislation used for the implementation must be decided according to the country's specific legal system. A law might be necessary or a decree may be sufficient. In general, the faster the adoption of the legal instrument can be achieved, the better.

One proven method for tackling comprehensive licensing reforms is to bundle the licensing-related reform bills and include them in the annual budgeting process. This

\footnotetext{
37 See section 2.11 for more on the legal strategy.
} 
method ensures that there is adherence to a specific deadline, government scrutiny of the budgetary impact of the proposals, and one-time review of the bills in a comprehensive package rather than on a piecemeal basis. The bundling approach also strengthens the likelihood of impact, since implementing instructions can be disseminated at once and systematically to regulators and other government bodies.

This approach was successfully adopted in the Netherlands, as well as in Kenya, for example. World Bank Group (2007) identifies it as one of the key success factors of the Dutch regulatory reforms: "the program's innovative design - a 25 percent target reduction in regulatory costs, a link between regulatory reforms and the budget cycle, and the establishment of the Dutch Advisory Board on Administrative Burden (ACTAL) as an independent watchdog of the reforms - lies behind the success. These features are now being adopted by other countries around the world."

\subsection{The Last Mile: Ensuring Reforms are Effective in Practice}

After the new legislation has been adopted and come into force, it has to be implemented and effectively communicated. This is an essential step - the last mile to complete the race — in ensuring that reforms are effective. Without it, much of the effort to date will be in vain.

Reforms are about changing behavior, not just changing the law. Reforms will be effective and have an impact only when the new regime is fully implemented by regulatory agencies (the owners of the new processes), and businesses are fully aware of the changes, thus adjusting their behavior to the new regime.

This will likely mean significant changes in the way regulatory agencies function: processes will have to be re-engineered; departments reorganized; forms rewritten; job descriptions adjusted and officials trained accordingly; information made publicly available; and other such measures.

Outreach to the business community, the primary beneficiary of the reforms, will be crucial to ensure effective implementation. Fully aware of the changes, businesses (and business associations in particular) may play an important role in ensuring that the new rules are implemented. By expecting change, businesses may also help speed up this process. As mentioned in Section 1.6, relying on official communication channels, such as speeches by ministers, reports to parliament, Web site information, and stories on the government's Web site will not be enough. A more effective communications strategy will consider the following (see Box 5 for more):

- Choose known spokespersons from the business community.

- Use mass communication channels (television, newspapers, radio). 
- Organize public events with businesses.

- Use comparisons with other countries.

It is hard to estimate the time and effort needed to complete this step. It should be made clear that the step can be particularly tedious and time-consuming depending on the number and depth of the reforms.

\subsection{Introducing an Electronic Registry of All Valid Licenses}

A successful licensing reform remains successful if it is guaranteed that abolished licenses and requirements do not creep back into the system after completion of the reform. A good way to achieve this goal is the establishment of an electronic regulatory registry (e-registry), that includes electronically accessible forms for all valid business licenses in the country. Additionally, the e-registry will provide enhanced legal security for businesses: only business licenses in the registry will be legal and enforceable.

Easy access to information about regulation is part of international good practice for business regulation. An accessible, comprehensive and central registry of business regulation contributes significantly to improving regulatory transparency, and to reducing regulatory risk and uncertainty for businesses.

At a later stage, the content of the e-registry can be gradually expanded to include other types of business regulation. The formats of forms available online can be progressively developed to self-generate business data already provided. The content of the e-registry should also be made electronically available to regulating authorities, thereby enabling regulatory transactions to be carried out online.

The functions of the e-registry, once established, will be almost exclusively of a technical nature. Primary tasks will consist of entering licenses (and other forms of business regulation) that have passed the technical, regulatory, and political screening process into the e-registry. The functions of the e-registry, described in Box 19, will be distinctively different from the scrutiny functions to be exercised by a regulatory reform unit (described in the section below).

This step should explore links with other e-government initiatives. Additionally, it is important to note that in principle, it will require substantial contribution in-kind from government, including staff working at the registry.

When making an entry about a license into the register, certain information must be submitted by the regulatory authority to the registry along with the name of the license itself. Based on discussions in Kenya, international experience in general and special input from 


\section{BOX 19 Principles and Responsibilities for an E-registry System}

- Entry into the register of license requirements should be a condition for the coming into force (validity and enforceability) of the license requirements lawfully adopted by the relevant regulatory authority

- Each regulatory authority should be responsible for submitting to the Legal Gazette (or equivalent) the announcement of new, amended or repealed subsidiary legislation and license requirements, including license application forms

- Each regulatory authority should be responsible for the contents and accuracy of new, amended, or repealed license requirements to be registered with the registry

- Each regulatory authority should be responsible for the reporting of new, amended, or repealed license requirements so the registry can perform continuous updating of the register

- Each regulatory authority shall be responsible for consolidating amended license requirements to be registered

- The registry shall be responsible for the accurate entry of license requirements as submitted by the regulatory body

- The registry shall be responsible for easy access to the information registered for all members of the public who request such information

Source: World Bank Group (2007)

the lessons learned in Mexico by the Federal Commission of Regulatory Improvement ${ }^{38}$, Box 20 includes suggestions for information that might be entered in the register for each license.

\section{BOX 20 Typical Information to Enter in an E-registry}

- Name (title) and identification of the business license, including a unique code

- Justification of the business licensing requirement (the purpose)

- Reference to the governing legislation with chapter number and section, and if possible the URL

- Full legal text of the business license requirement, possibly through a URL

- Date of publication in the Gazette (or equivalent)

- Date of coming into force (as notified in the license regulation)

- Date of entry into register (being enforceable)

- License period or validity (the period for which the license is valid)

- Application fee

- License fee

- Any other fees that a business must pay in the process of getting the license, (for example, investigations, inspections, processing fees)

\footnotetext{
${ }^{38}$ See: www.cofemer.gob.mx for the official Web site (in Spanish). Click on Registo de Tramites y Servicios Federales to access the e-registry. The Web site includes a search engine.
} 


\section{Box 20 Typical Information to Enter in an E-registry (continued)}

- A complete list of requirements - documents and information required from the business entity applying for a license

- Resolution criteria - an explanation of how the regulatory authority would accept or reject an application

- Maximum processing time, in which the regulatory authority has to respond to the application for the business activity, and if the principle "silence is consent" is applied

- Any form(s), if applicable

- Identification of agency - name of the licensing agency (the regulatory authority), name of the department or division of the licensing agency, business hours, and name and contact information of the person who can answer questions about the license

- Contacts - names, addresses, telephone and fax numbers, and e-mails of the public offices where necessary formalities can be submitted, as well as any other information that allows the submission of consultations, documents and complaints

Source: World Bank Group (2007) Box 20 Typical Information to Enter in an E-registry

\subsection{Monitoring and Evaluation: Project Completion, Evaluation and Lessons Learned}

In earlier phases of the reform process (see Section 1.18 for more on the design of the M\&E framework), a monitoring framework has been established, including choice of indicators, baseline, and targets. Monitoring also involved gathering information and data points about the reform's achievements, and where it stands with regard to its objectives. This section focuses on the evaluation part of M\&E, which aims at assessing whether or not the reforms have delivered the expected results. The M\&E framework also provides a good opportunity to explore factors behind specific success or failure elements of the reform to learn from them and inform further business licensing projects.

For more details, please refer to the chapter on evaluation in IFC, GTZ, and DFID (2008), which examines strategies and tactics for responding to the challenges of assessing impact, and particularly in answering the following questions:

- What has been achieved and what benefits have come from the changes made by an intervention?

- What, if any, results can be attributed to any given intervention?

- To what extent would changes and results have occurred without the intervention? 



\section{Chapter 5: Broadening the Scope of Reform Beyond Licensing}

Reforms that produce lasting improvements for business operations generally require systemic changes. Indeed, one-time reforms focused only on the licensing regime are unlikely to have long-lasting impact on the private sector's confidence in investing in a country.

Successful reforms are not just about cutting the immediate red tape and addressing the symptoms, but also about addressing the causes or the institutional factors that led to these obstacles in the first place. Sustainable good regulatory performance often requires systemic changes in the way regulation is prepared, scrutinized and enforced. A series of steps can be taken that will help ensure that the results from business licensing reforms will endure in the long run, including:

- a review of regulatory management capacity;

- institutionalization of a regulatory reform unit at the core of government;

- introduction of vetting mechanisms for new regulations; and

- drafting of a business regulation bill, if needed.

\subsection{Implementing the Medium-Term Regulatory Reform Strategy}

A draft regulatory reform strategy would have already been elaborated in the course of the second stage of the project. Section 2.10 provides the main rationales for such a strategy, which aims at targeting and prioritizing regulatory reform efforts over a period of typically three to five years.

The responsibility for elaboration and implementation of the regulatory reform strategy should rest with the reform team in order to assure an integrated approach to the various reform components. To better inform considerations about continued and more broad-based 
systemic reform of the way regulatory interventions are prepared and implemented, a review of regulatory management capacities could be conducted.

A regulatory management capacity review typically involves a mapping and analysis of current regulatory institutions and processes. The rationale and relevance of this review is based on the assumption that, in order for governments to sustain reform, significant efforts are required to improve the systemic (institutional) capacities to produce good business regulation. The regulatory capacity review will provide decision makers with information about areas in need of attention and, more importantly, specific proposals for addressing them.

The output of this exercise, which is typically carried out with the support of a local consultant, will be an analytical report with recommendations on how to improve regulatory capacities, institutions and processes. This is most likely a stand-alone report, which directly feeds into the implementation of the proposed regulatory reform strategy.

As mentioned in Section 2.10, broader regulatory reforms are likely to encompass inspections and enforcement of licensing and other forms of business regulations. This may have already been articulated in a medium-term regulatory reform strategy. Several sources can help project teams design and implement reforms of inspections, including:

- IFC (2006b), which examines good practices of effective business inspections

- Coolidge (2006), a brief note offering models for inspections reform.

\subsection{Establishing a Regulatory Reform Unit at the Core of Government}

Credible mechanisms to vet all new draft regulations before promulgation and submission to Cabinet or Parliament should be designed and implemented as a further step to advance the regulatory reform agenda. Reviewing and vetting new regulations could be the function of a Regulatory Reform Unit (RRU), a permanent, cross-ministerial institution at the core of government. The RRU could help improve coordination within the administration and at different levels of government and help institutionalize regulatory management of the system. The RRU could be built from the ground laid by the reform committee, by adapting and turning this ad hoc committee into a permanent body with new functions and more responsibilities, as was successfully done in Mexico (See Box 21).

The successful licensing reform will have streamlined the current stock of business licenses. To ensure long-term sustainability of reform gains, a mechanism is needed to address the flow of new regulations: through review and vetting of all new draft regulation, to be assessed against the same quality criteria applied during the reform. The approach is inspired from and may take the form of an adapted lighter version of the Regulatory Impact Analysis (RIA) system. This is a function that the RRU could lead. 
The mandate of the RRU will require strong political endorsement. A detailed action plan will need to be elaborated, including terms of reference for the unit and for a chairperson. The plan must also address identification of suitable members, its mandate, and legal underpinning.

Certain resources would need to be given to the RRU in order to support its role as advocate for regulatory reform. As the unit responsible for these efforts, communications

\section{BOX 21 Institutionalizing Regulatory Reform - The Case of Mexico}

In the late 1980s, the government of Mexico assembled a small, high-level group of professionals - similar to a special forces team - outside the traditional structures of the bureaucracy to implement the radical new policy process of regulatory reform. These professionals, around 15 economists and lawyers, formed the Economic Deregulation Unit (UDE), created in 1989. The UDE operated under the general purview of the powerful trade ministry (Secofi) and was directly accountable to the trade minister.

At the beginning, the UDE directed much of its efforts toward fostering efficiency in the provision of non-traded goods and services that were shielded from international market competition. It used an opportunistic strategy, selecting economic sectors where deregulation could yield large gains at little political cost, such as natural gas, or where inaction would result in excessively high costs, such as road freight. But the UDE soon found that it could not address the regulatory problems facing the economy unless it moved from a strategy of deregulation to a broader and more sustainable strategy of regulatory improvement.

The new strategy was aimed at improving the regulatory environment for private sector activity by creating appropriate market rules and institutions and building more effective and efficient governance. The UDE began to devote great efforts to horizontal regulatory reforms that benefited virtually all economic sectors. In a move designed to make the regulatory reform program more systematic and transparent, President Zedillo issued a decree, the Agreement for the Deregulation of Business Activity, in December 1995. Now with a broader mandate, the UDE established a clear review process for proposed and existing regulations. This process required the sponsoring agencies to justify proposed regulatory measures on the basis of efficiency.

One of the UDE's major achievements was to create a complete inventory of business formalities - rules and forms required to start and operate a business, such as licenses, permits, and other authorizations. The process of compiling this inventory, the Federal Registry of Business Formalities, involved reviewing all business formalities (except those relating to taxes). In addition, the UDE required ministries and agencies to submit a justification for each one, a requirement that shamed officials into culling unneeded, duplicative, and forgotten formalities. The process led to the elimination of 45 percent of business formalities by 1999, reducing red tape and the discretion of frontdesk public servants and inspectors. By reducing and streamlining the federal formalities required to start a new business, the changes not only made business start-up far easier; they also virtually eliminated a significant source of corruption. Other initiatives included transforming licenses into notifications, exempting or simplifying compliance by small firms, and simplifying and streamlining inspection procedures. The UDE also began to work with local governments to establish state and municipal registries of formalities.

Source: World Bank Group (2008), Regulatory Transformation in Mexico, 1988-2000. 
and education campaigns are important to inform the public about the benefits of reform. The RRU has to be staffed with skilled people, as one of its main functions should be to build capacities for regulatory reform inside the administration. The RRU could normally provide training to regulators so they can get familiarized with the use of Regulatory Impact Analysis.

\subsection{Ensuring Quality of Future Regulations: Regulatory Impact Analysis}

RIA is a policy tool that allows governments to examine the implications of potential regulatory policy options through the establishment of a rational decision policy framework $^{39}$. The systemic process of questioning at the beginning of the policy cycle facilitates reflection on the important range of details that have to be taken into account when designing and implementing regulation, in particular related to the options available when governments have to make regulatory decisions.

RIA also helps governments to assess the impacts of regulation and is used to measure the likely benefits, costs, and effects of new or existing regulations. RIA is an essential policy tool for regulatory quality because its overall aim is to help governments make their policies more efficient. The use of RIA can contribute to the policymaking process by promoting efficient regulatory policy.

As an institutionalized model for analysis ${ }^{40}$ RIA should follow seven basic steps, described in Box 22. In its practical application, RIA commences with an analysis and articulation of the policy problem that creates the context for possible regulation. It highlights the different objectives and options available to tackle it, using regulatory measures, but also alternatives to regulation. The impact analysis should consider an evaluation of the costs and benefits of the selected options, in a quantitative way. A RIA should indicate the way forward and explain how the selected option will be implemented and reviewed over time.

RIA can be fundamental to complement licensing reform efforts since it is a mechanism to improve the quality of new and existing regulation. RIA can be integrated in broad programs of regulatory reform to keep momentum and make more long-term improvements in the system. A number of minimum requirements are fundamental for establishing an RIA light system ${ }^{41}$ :

- High-level political commitment

- Regulatory review unit or group

\footnotetext{
39 See www.oecd.org/dataoecd/21/52/35258511.pdf.

40 See www.oecd.org/dataoecd/44/15/40984990.pdf.

${ }^{41}$ See World Bank Group (forthcoming), Regulatory Reform in Developing Countries: the Role of Regulatory Impact Analysis (RIA).
} 


\section{Box 22 Seven Key Steps in a Regulatory Impact Analysis}

RIA should be used for the most important regulations and should be done early in the policymaking process. The following elements should be taken into account to prepare a high-quality RIA that meets governments' objectives and provides information for decision making:

1. Problem. This is a key step to identify and document the problem (sources, further action required, risks related, magnitude of the change and size of the problem, who might be affected, and so on).

2. Objective(s). This step should help define why government action is required and what needs to change.

3. Options. This step should indicate the possible options (feasible and non-feasible) with explanations and descriptions for each one of them.

4. Impact analysis. This step should include the use of a method that is linked to the magnitude of the problem, assessing impacts of all relevant factors.

5. Consultation. This step includes a list of who was consulted, how and what the views of stakeholders are.

6. Conclusion and recommended way forward. This step indicates which option was chosen and why others were not. The preferred option has to achieve the objective.

7. Implementation and review. This step has to indicate how the preferred option will be implemented, monitored, and enforced.

- Consistent criteria and rules

- Transparency and consultation

- Capacity-building

Project teams can find out more on the RIA process by taking an introductory course on the United Kingdom's Department for Business Enterprise and Regulatory Reforms (BERR) website $^{42}$. The introduction explains the steps in completing an impact assessment, as well as who should be involved throughout the process.

\subsection{Exploring the Need for Business Regulations Bill}

Following the reform of the licensing regime, the extension of the scope of reform to broader regulations, and the introduction of institutional mechanisms to improve the quality of future regulations, it may be worth exploring the introduction of a Business Regulations Bill (BRB). The objective of such a bill is to establish a legal

\footnotetext{
42 See www.iatraining.berr.gov.uk.
} 
framework and focal point for all business regulations, with guiding principles for the long term.

BRBs can cover key systemic aspects of a regulatory management system. Their main object is to provide a framework for the activities of authorities involved in the regulation of businesses.

BRBs generally:

- provide guiding principles for regulatory agencies to follow;

- provide general principles and criteria for business regulations;

- establish a central electronic register of all legislation and requirements pertaining to business regulations;

- establish or nominate institutions responsible for regulatory review and quality (such as a regulatory reform unit at the center of government, a senior policy-level committee, or external advisory boards); and

- define or authorize a minister to define processes for regulatory review (RIA).

BRBs are just one part of the legal body that regulates business activities. At the international level there is no general trend on having such a bill, but several countries with legal systems with no clear focus on business regulations have opted for a BRB. In general, countries enact a wide range of scattered laws and regulations dealing with business regulations $^{43}$. The benefit of having one BRB is that such a legal document can be seen as a comprehensive framework for business regulations that introduces principles of good regulation by clarifying concepts, adapting general criteria for business regulations, assigning clear regulatory quality functions to specific institutions, and establishing by law procedures for better regulation.

To be successful, a BRB should avoid setting a rigid framework for business regulations. Since the scope of regulatory reform is incremental in countries trying to improve the creation, implementation, and enforcement of regulations, a BRB should be functional and flexible to adapt over time to the changes required. But a BRB should also set up clear sanctions for the regulators that do not comply with the new procedures to create new regulation.

\footnotetext{
43 The Law Library of the Doing Business project (www.doingbusiness.org/LawLibrary) provides many examples of business laws and regulations around the world. However, there are very few examples of Business Regulations Laws/Bills" as such.
} 


\section{Annexes}

\section{Index of Annexes}

Annex 1 Summary Table: Standard Stages and

Steps to Implement Business Licensing Reform 53

Annex 2 Information Collection Template for Licenses and Permits 60

Annex 3 Terms of Reference: Inventory of Business Licenses - Local Consultant 63

Annex 4 Terms of Reference: SCM Benchmarking of Compliance Costs 69

Annex 5 Terms of Reference: Chairperson of the Reform Committee 72

Annex 6 Outline for Decision Memos of the Reform Committee 75 



\section{ANNEX 1}

\section{Summary Table: Standard Stages and Steps to Implement Business Licensing Reform}

\begin{tabular}{|c|c|c|c|}
\hline Step & Purpose & Output & Example/Comment \\
\hline $\begin{array}{l}\text { 1. Desk review } \\
\text { of existing } \\
\text { diagnostics }\end{array}$ & $\begin{array}{l}\text { To determine in advance } \\
\text { of scoping mission key } \\
\text { problems with licensing }\end{array}$ & Decision go/no go & $\begin{array}{l}\text { (Investment Climate } \\
\text { Assessments, Doing Business; } \\
\text { non-World Bank Group) }\end{array}$ \\
\hline $\begin{array}{l}\text { 2. Stakeholder } \\
\text { and political } \\
\text { economy analysis }\end{array}$ & $\begin{array}{l}\text { To identify powerful } \\
\text { champion(s) } \\
\text { To understand political } \\
\text { dynamics (budget cycle, etc.) }\end{array}$ & $\begin{array}{l}\text { Primary counterpart } \\
\text { and timeline } \\
\text { identified in the } \\
\text { scoping report }\end{array}$ & $\begin{array}{l}\text { Ministry of Finance } \\
\text { partnering with Ministry of } \\
\text { Trade and Industry in Kenya }\end{array}$ \\
\hline $\begin{array}{l}\text { 3. Preliminary } \\
\text { diagnostic } \\
\text { (scoping) mission }\end{array}$ & $\begin{array}{l}\text { Interviews and fact-finding } \\
\text { mission to confirm findings } \\
\text { of desk review }\end{array}$ & $\begin{array}{l}\text { Extent of problem } \\
\text { assessed and } \\
\text { confirmed }\end{array}$ & $\begin{array}{l}\text { Should include subnational } \\
\text { fiscal issues from start }\end{array}$ \\
\hline $\begin{array}{l}\text { 4. Presentation } \\
\text { to government } \\
\text { counterpart }\end{array}$ & $\begin{array}{l}\text { To present reform approach } \\
\text { to champion and other } \\
\text { stakeholders; gauge } \\
\text { commitment }\end{array}$ & $\begin{array}{l}\text { Presentation, } \\
\text { showing preliminary } \\
\text { findings and } \\
\text { example of } \\
\text { successful reform }\end{array}$ & $\begin{array}{l}\text { Consider peer-to-peer } \\
\text { learning as in Madagascar, } \\
\text { where a presentation by } \\
\text { Head of Kenya Reform } \\
\text { Committee was used to } \\
\text { showcase a successful reform }\end{array}$ \\
\hline $\begin{array}{l}\text { 5. Obtaining a } \\
\text { Letter of Request }\end{array}$ & $\begin{array}{l}\text { To demonstrate and } \\
\text { document interest/ } \\
\text { commitment from the } \\
\text { government }\end{array}$ & & \\
\hline $\begin{array}{l}\text { 6. Media and } \\
\text { communications } \\
\text { strategy }\end{array}$ & $\begin{array}{l}\text { To help champion sell reform } \\
\text { to all stakeholders } \\
\text { To ensure champion's } \\
\text { commitment and promote } \\
\text { reform implementation }\end{array}$ & $\begin{array}{l}\text { Media campaigns, } \\
\text { press releases, etc. }\end{array}$ & $\begin{array}{l}\text { Consider: Which media, } \\
\text { what message, when? }\end{array}$ \\
\hline $\begin{array}{l}\text { 7. Political } \\
\text { decision showing } \\
\text { high-level } \\
\text { endorsement }\end{array}$ & $\begin{array}{l}\text { To signal to all licensing } \\
\text { authorities the high level of } \\
\text { support for the reform; } \\
\text { To publicly launch the reform }\end{array}$ & Cabinet Decree & \\
\hline
\end{tabular}




\begin{tabular}{|c|c|c|c|}
\hline Step & Purpose & Output & Example/Comment \\
\hline $\begin{array}{l}\text { 8. Outreach } \\
\text { strategy with } \\
\text { executive bodies }\end{array}$ & $\begin{array}{l}\text { To publicize government } \\
\text { endorsement of reform } \\
\text { To secure buy-in from } \\
\text { administration and } \\
\text { regulatory agencies }\end{array}$ & $\begin{array}{l}\text { Letter from } \\
\text { leading Ministers } \\
\text { (champions) to } \\
\text { all regulators / } \\
\text { administrations }\end{array}$ & $\begin{array}{l}\text { Key step in ensuring active } \\
\text { involvement of regulatory } \\
\text { agencies in the reform } \\
\text { process }\end{array}$ \\
\hline $\begin{array}{l}\text { 9. Building a } \\
\text { comprehensive } \\
\text { inventory of all } \\
\text { existing licenses }\end{array}$ & $\begin{array}{l}\text { To capture comprehensive } \\
\text { baseline information on } \\
\text { existing licenses } \\
\text { To serve as benchmark for } \\
\text { the work of the Reform } \\
\text { Committee and basis for } \\
\text { monitoring and evaluation }\end{array}$ & $\begin{array}{l}\text { One Information } \\
\text { Collection Template } \\
\text { should be filled out } \\
\text { for each license }\end{array}$ & $\begin{array}{l}\text { Inventory starts with a list } \\
\text { of existing licenses, based } \\
\text { on review of legislation, } \\
\text { followed by "real-life" } \\
\text { information gathered } \\
\text { through surveys and focus } \\
\text { groups with operators; } \\
\text { International Consultant } \\
\text { to train and oversee local } \\
\text { consultant to ensure } \\
\text { data can be used in SCM } \\
\text { calculation }\end{array}$ \\
\hline $\begin{array}{l}\text { 10. Standard } \\
\text { Cost Model } \\
\text { benchmarking }\end{array}$ & $\begin{array}{l}\text { To assess cost of compliance } \\
\text { imposed on businesses by } \\
\text { licensing regime through } \\
\text { SCM methodology }\end{array}$ & $\begin{array}{l}\text { SCM spreadsheet; } \\
\text { filled on the basis of } \\
\text { the inventory }\end{array}$ & $\begin{array}{l}\text { Info Collection Template } \\
\text { should be capturing the info } \\
\text { required for SCM analysis }\end{array}$ \\
\hline $\begin{array}{l}\text { 11. Setting } \\
\text { quantitative } \\
\text { reform targets }\end{array}$ & $\begin{array}{l}\text { To establish and publicize } \\
\text { reform targets in terms of } \\
\text { reduction (savings) in costs } \\
\text { and time for the economy }\end{array}$ & $\begin{array}{l}\text { Publicized reform } \\
\text { target, as part of } \\
\text { mandate }\end{array}$ & $\begin{array}{l}30 \% \text { burden reduction has } \\
\text { been a realistic target for } \\
\text { first-generation reforms }\end{array}$ \\
\hline $\begin{array}{l}\text { 12. Establishing } \\
\text { the reform } \\
\text { committee with } \\
\text { explicit mandate }\end{array}$ & $\begin{array}{l}\text { To constitute team of } \\
\text { reformers committed/ } \\
\text { dedicated to reform } \\
\text { implementation }\end{array}$ & $\begin{array}{l}\text { Reform committee } \\
\text { chair + members } \\
\text { nominated } \\
\text { Reform committee } \\
\text { operational; and } \\
\text { made public through } \\
\text { legal gazette }\end{array}$ & $\begin{array}{l}\text { Key ministries represented; } \\
\text { Individuals nominated (and } \\
\text { named); Review criteria } \\
\text { publicly endorsed }\end{array}$ \\
\hline $\begin{array}{l}\text { 13. Validation } \\
\text { workshop of } \\
\text { inventory findings }\end{array}$ & $\begin{array}{l}\text { To strengthen momentum } \\
\text { for reform } \\
\text { To strengthen the reform } \\
\text { committee's mandate } \\
\text { To "shame" special interests }\end{array}$ & $\begin{array}{l}\text { Post-inventory } \\
\text { review to publicize } \\
\text { and validate } \\
\text { findings with } \\
\text { all stakeholders } \\
\text { (including private } \\
\text { sector) }\end{array}$ & $\begin{array}{l}\text { Will also introduce and set } \\
\text { the framework for regulatory } \\
\text { reform strategy }\end{array}$ \\
\hline $\begin{array}{l}\text { 14. Identifying } \\
\text { quick wins to } \\
\text { spur momentum }\end{array}$ & $\begin{array}{l}\text { To propose easy-to- } \\
\text { implement reforms that } \\
\text { matter to private sector } \\
\text { To strengthen reform } \\
\text { momentum }\end{array}$ & $\begin{array}{l}\text { Quick wins report } \\
\text { proposing set of } \\
\text { easy, stroke-of-a- } \\
\text { pen type reforms }\end{array}$ & $\begin{array}{l}\text { Needs to be validated by } \\
\text { private sector (hence follows } \\
\text { workshop) }\end{array}$ \\
\hline $\begin{array}{l}\text { 15. Selecting } \\
\text { high priority } \\
\text { licenses }\end{array}$ & $\begin{array}{l}\text { To focus reform efforts on } \\
\text { licenses that have heavy } \\
\text { economic impact and matter } \\
\text { to businesses }\end{array}$ & $\begin{array}{l}\text { List of priority } \\
\text { licenses }\end{array}$ & $\begin{array}{l}\text { Business associations to } \\
\text { come up with a short list }\end{array}$ \\
\hline
\end{tabular}




\begin{tabular}{|c|c|c|c|}
\hline Step & Purpose & Output & Example/Comment \\
\hline $\begin{array}{l}\text { 16. Drafting a } \\
\text { medium-term } \\
\text { Regulatory Reform } \\
\text { Strategy (RRS) }\end{array}$ & $\begin{array}{l}\text { To elaborate a medium- } \\
\text { term, broader strategy } \\
\text { moving beyond licensing }\end{array}$ & $\begin{array}{l}\text { Reg Ref Strategy } \\
\text { and Action Plan }\end{array}$ & $\begin{array}{l}\text { Leverages success and } \\
\text { momentum created by } \\
\text { licensing reform }\end{array}$ \\
\hline $\begin{array}{l}\text { 17. Identifying } \\
\text { a strategy } \\
\text { for the legal } \\
\text { implementation } \\
\text { of reforms }\end{array}$ & $\begin{array}{l}\text { To identify legal } \\
\text { implementation options } \\
\text { (packaged vs. partial) }\end{array}$ & $\begin{array}{l}\text { Potential legal } \\
\text { implementation } \\
\text { vehicles and timing } \\
\text { identified: } \\
\text { - repeals and } \\
\text { amendments to } \\
\text { licenses } \\
\text { - budget law } \\
\text { - business } \\
\text { regulation bill } \\
\text { - short-term } \\
\text { vetting, etc.) }\end{array}$ & $\begin{array}{l}\text { In Kenya, linking reforms } \\
\text { to budget process proved } \\
\text { critical }\end{array}$ \\
\hline $\begin{array}{l}\text { 18. Designing } \\
\text { a monitoring } \\
\text { and evaluation } \\
\text { framework }\end{array}$ & $\begin{array}{l}\text { To agree with client on } \\
\text { measurable reform targets } \\
\text { and track them } \\
\text { To monitor reform } \\
\text { committee progress and } \\
\text { performance }\end{array}$ & $\begin{array}{l}\text { Measurable reform } \\
\text { targets agreed upon } \\
\text { with client }\end{array}$ & $\begin{array}{l}\text { Doing Business indicators } \\
\text { often high on the client's } \\
\text { agenda } \\
\text { Inventory should also } \\
\text { generate relatively firm } \\
\text { baseline data, ultimately } \\
\text { part of the regulatory reform } \\
\text { strategy; } \\
\text { M\&E for project also needed }\end{array}$ \\
\hline $\begin{array}{l}\text { 19. Design } \\
\text { license } \\
\text { information } \\
\text { database }\end{array}$ & $\begin{array}{l}\text { To build a software } \\
\text { database, as receptacle } \\
\text { of information gathered } \\
\text { for each license through } \\
\text { template }\end{array}$ & $\begin{array}{l}\text { Spreadsheet } \\
\text { containing the } \\
\text { license inventory } \\
\text { database }\end{array}$ & $\begin{array}{l}\text { Database must reflect the } \\
\text { entries of the inventory } \\
\text { template }\end{array}$ \\
\hline $\begin{array}{l}\text { 20. Engaging } \\
\text { with regulatory } \\
\text { agencies: reversal } \\
\text { of burden of } \\
\text { proof }\end{array}$ & $\begin{array}{l}\text { To request feedback } \\
\text { from regulators, with } \\
\text { credible sanctions for } \\
\text { non-compliance, applying } \\
\text { the "reversal of burden of } \\
\text { proof" principle; } \\
\text { To file and process the } \\
\text { incoming responses; } \\
\text { To follow-up on questions, } \\
\text { incomplete or absent } \\
\text { responses }\end{array}$ & $\begin{array}{l}\text { One template } \\
\text { filled by regulatory } \\
\text { agencies per each } \\
\text { existing license to } \\
\text { justify its existence } \\
\text { Reminder letters to } \\
\text { agencies, etc. }\end{array}$ & $\begin{array}{l}\text { Complementary strategies: } \\
\text { request to ministers, } \\
\text { follow-up by reform } \\
\text { committee, involvement } \\
\text { of private sector; (legal) } \\
\text { consultant to do cross- } \\
\text { checking } \\
\text { Likely to be time-consuming. } \\
\text { Reform committee secretariat } \\
\text { needs to be sufficiently } \\
\text { staffed }\end{array}$ \\
\hline $\begin{array}{l}\text { 21. Special } \\
\text { attention to } \\
\text { sectoral reviews }\end{array}$ & $\begin{array}{l}\text { To conduct reviews through } \\
\text { a sectoral or industry lens; } \\
\text { reform proposals based on } \\
\text { industry logic }\end{array}$ & $\begin{array}{l}\text { Sectoral or industry } \\
\text { reports }\end{array}$ & $\begin{array}{l}\text { May be necessary to hire } \\
\text { sectoral experts applying } \\
\text { general and government- } \\
\text { endorsed criteria to sector }\end{array}$ \\
\hline
\end{tabular}




\begin{tabular}{|c|c|c|c|}
\hline Step & Purpose & Output & Example/Comment \\
\hline $\begin{array}{l}\text { 22. Rationalizing } \\
\text { the system of } \\
\text { local taxes, fees } \\
\text { and charges }\end{array}$ & $\begin{array}{l}\text { To identify measures to } \\
\text { compensate for legitimate } \\
\text { revenue loss incurred by } \\
\text { local governments as result } \\
\text { of reform. Must be tailored } \\
\text { to fiscal decentralization } \\
\text { architecture }\end{array}$ & $\begin{array}{l}\text { Subnational } \\
\text { regulation and tax } \\
\text { report } \\
\text { Assessment } \\
\text { of revenue } \\
\text { implications }\end{array}$ & \\
\hline $\begin{array}{l}\text { 23. Review of } \\
\text { licenses by the } \\
\text { reform committee }\end{array}$ & $\begin{array}{l}\text { To conduct the review of } \\
\text { every identified license } \\
\text { To assess each license } \\
\text { against established review } \\
\text { criteria }\end{array}$ & $\begin{array}{l}\text { Several working } \\
\text { sessions of the } \\
\text { reform committee }\end{array}$ & $\begin{array}{l}\text { The most intense workload } \\
\text { for the reform committee. } \\
\text { Dedicating 2- to 3-day } \\
\text { retreats outside of capital city } \\
\text { can be an efficient way to } \\
\text { complete the review }\end{array}$ \\
\hline $\begin{array}{l}\text { 24. Preparing } \\
\text { Decision Memos } \\
\text { for government } \\
\text { approval }\end{array}$ & $\begin{array}{l}\text { To produce one Decision } \\
\text { Memo per reviewed license } \\
\text { including (a) decision to } \\
\text { keep, streamline or abolish, } \\
\text { and (b) justification of } \\
\text { decision }\end{array}$ & $\begin{array}{l}\text { One Decision Memo } \\
\text { per identified } \\
\text { license }\end{array}$ & $\begin{array}{l}\text { Decision Memos should } \\
\text { ideally include the } \\
\text { assessment (based on SCM) } \\
\text { of savings in costs and time } \\
\text { implied by recommendations }\end{array}$ \\
\hline $\begin{array}{l}25 . \text { Political and } \\
\text { communications } \\
\text { strategy to } \\
\text { support adoption } \\
\text { of reform }\end{array}$ & $\begin{array}{l}\text { To validate findings and } \\
\text { ensure support for reform }\end{array}$ & $\begin{array}{l}\text { Consultations } \\
\text { and workshops } \\
\text { with government } \\
\text { agencies and } \\
\text { stakeholders to } \\
\text { discuss preliminary } \\
\text { findings }\end{array}$ & \\
\hline $\begin{array}{l}\text { 26. Legal } \\
\text { implementation } \\
\text { of decisions }\end{array}$ & $\begin{array}{l}\text { Government to submit draft } \\
\text { legislation/amendment for } \\
\text { approval by Parliament/ } \\
\text { Cabinet }\end{array}$ & $\begin{array}{l}\text { Approved } \\
\text { legislation; decree; } \\
\text { amendment } \\
\text { following } \\
\text { recommendations }\end{array}$ & \\
\hline $\begin{array}{l}\text { 27. Ensuring } \\
\text { reforms are } \\
\text { effective in } \\
\text { practice }\end{array}$ & $\begin{array}{l}\text { To build the capacity of } \\
\text { regulatory agency staff to } \\
\text { pilot and implement new } \\
\text { procedures, following legal } \\
\text { changes }\end{array}$ & $\begin{array}{l}\text { New procedures } \\
\text { implemented } \\
\text { (change has } \\
\text { materialized); } \\
\text { Outcome captured } \\
\text { by M\&E }\end{array}$ & \\
\hline $\begin{array}{l}\text { 28. Electronic } \\
\text { registry of all valid } \\
\text { licenses }\end{array}$ & $\begin{array}{l}\text { To set the framework for } \\
\text { positive legal security (i.e. } \\
\text { only licenses in the registry } \\
\text { can be enforced) } \\
\text { To strengthen transparency, } \\
\text { accessibility, and } \\
\text { enforcement }\end{array}$ & $\begin{array}{l}\text { E-registry legally } \\
\text { and physically } \\
\text { established (incl. } \\
\text { staff dedicated to } \\
\text { running it) }\end{array}$ & $\begin{array}{l}\text { Judiciary not enough to } \\
\text { ensure enforcement; } \\
\text { Explore links with other } \\
\text { e-government initiatives }\end{array}$ \\
\hline
\end{tabular}




\begin{tabular}{|c|c|c|c|}
\hline Step & Purpose & Output & Example/Comment \\
\hline $\begin{array}{l}\text { 29. M\&E: project } \\
\text { completion, } \\
\text { evaluation, and } \\
\text { lessons learned }\end{array}$ & $\begin{array}{l}\text { To explore factors behind } \\
\text { specific success or failure } \\
\text { elements of the reform } \\
\text { to inform further reform } \\
\text { efforts. }\end{array}$ & Evaluation report & \\
\hline $\begin{array}{l}\text { 30. Reviewing } \\
\text { regulatory } \\
\text { management } \\
\text { capacity }\end{array}$ & $\begin{array}{l}\text { To improve the systemic } \\
\text { (i.e. institutional) capacities } \\
\text { to produce good business } \\
\text { regulation }\end{array}$ & $\begin{array}{l}\text { Report on how to } \\
\text { improve regulatory } \\
\text { capacities, } \\
\text { institutions, and } \\
\text { processes }\end{array}$ & \\
\hline $\begin{array}{l}\text { 31. Establishing a } \\
\text { regulatory reform } \\
\text { unit }\end{array}$ & $\begin{array}{l}\text { To design and implement } \\
\text { credible mechanisms } \\
\text { to review and vet all } \\
\text { new draft regulations } \\
\text { before promulgation and } \\
\text { submission to Cabinet/ } \\
\text { Parliament: }\end{array}$ & $\begin{array}{l}\text { Permanent } \\
\text { Regulatory Reform } \\
\text { Unit established } \\
\text { within leading } \\
\text { Ministry (incl. staff) }\end{array}$ & \\
\hline $\begin{array}{l}\text { 32. Ensuring } \\
\text { Regulatory } \\
\text { Quality: } \\
\text { Regulatory Impact } \\
\text { Analysis }\end{array}$ & $\begin{array}{l}\text { To examine the implications } \\
\text { (incl. economic impact) } \\
\text { of regulatory policy } \\
\text { options through screening } \\
\text { mechanisms for new } \\
\text { regulations }\end{array}$ & $\begin{array}{l}\text { Unit in charge } \\
\text { of carrying out } \\
\text { Regulatory Impact } \\
\text { Analysis on new } \\
\text { business regulations }\end{array}$ & $\begin{array}{l}\text { Pre-conditions include: } \\
\text { strong high-level political } \\
\text { support; regulatory reform } \\
\text { unit in place; transparency; } \\
\text { consultation }\end{array}$ \\
\hline $\begin{array}{l}\text { 33. Exploring } \\
\text { the need for } \\
\text { a business } \\
\text { regulations bill }\end{array}$ & $\begin{array}{l}\text { To provide a framework for } \\
\text { the activities involved in the } \\
\text { regulation of businesses }\end{array}$ & & \\
\hline
\end{tabular}




\section{A.1 Key Documents Appearing Throughout the Reform's Lifecycle}

Some of the documents mentioned in the text and in the Summary Table, such as the Information Collection Template, the Inventory of Licenses, and Legal Acts, are not onetime only outputs - rather, they evolve during the course of a licensing project. Awareness of the documents' entire lifecycle during the project allows practitioners to design, implement, and sustain these documents throughout the project. The following boxes describe how each of the documents may evolve.

\section{Steps Involving the Use of the Information Collection Template}

The Information Collection Template is a questionnaire used to gather detailed information about the licenses under review. During the course of the licensing project, the template can be used in preparing the inventory of licenses, as a basis for implementing the SCM, and as a basis for assessing whether the license should be retained, eliminated or simplified, and provides important data to be entered into the electronic registry. The template is used in the following steps of the licensing reform project (see Summary Table in this annex):

- 9 - Inventory of all existing licenses

The template captures comprehensive baseline information on existing licenses.

- 10 - Standard Cost Model benchmarking

The template should capture the information needed for SCM analysis.

- 18 - Design license information database

The software database is the receptacle of information gathered for each license through the template.

- 19 - Involving regulating agencies: reversal of burden of proof

One template reviewed/filled by regulatory agencies per each existing license to justify its existence.

- 24 - Review of each identified license

Reform committee reviews every identified license based on the data in the template, and then assesses each license against established review criteria. It is therefore critically important that the information collected is accurate.

- 26 - Decision Memos

Decision memos (recommendations for government reform action) are based to a large extent on the data in the Information Collection Template.

- 30 - Electronic registry (e-registry) of all valid licenses

For the licenses that are retained after the reforms, the information collection template contains much information that can be posted in the electronic registry of valid licenses, including legal bases, regulatory agency, fees, processing time, and so on. 


\section{Steps Associated with the Inventory of Licenses}

The inventory of licenses is a master list of licenses imposed in a country. An accurate inventory serves as a baseline for the licensing reforms, and during the course of the project the team will refer to it regularly. The inventory of licenses comes up in the following steps during the licensing reform project:

\section{- 9 - Inventory of all existing licenses (template)}

An inventory of all (or selected) licenses is an initial diagnostic activity. It is critically important that the inventory is accurate, since important measurements and reform decisions will be made based on the inventory. As the project proceeds, it will be very difficult to revise the initial inventory, as such backtracking may call into question the entire baseline assessment and methodology — in effect, a blow to the credibility of the project.

- 12 - Validation workshop of inventory findings with private sector

The validation workshop is an opportunity to ensure that the inventory is accurate (see above), and it is one of the last chances to make revisions.

- 15 - Monitoring and Evaluation framework

At this stage, the inventory is one of the primary inputs into setting up the monitoring and evaluation framework for the licensing project. It denotes the number of licenses imposed in the country.

\section{- 30 - Electronic registry of all valid licenses}

The electronic registry is one of the final stages of the licensing reform as it contains the licenses that can validly be imposed on businesses and which have been retained from the original inventory because they met the criteria for legality, necessity, and business friendliness. Other licenses from the initial inventory will be streamlined; still others will be eliminated and not entered into the e-registry at all.

\section{Steps Involving Legal Acts}

Legal acts are the mechanism by which reforms are implemented by government. It is therefore important to plan at the outset what kind of legal instruments will be needed, and at which stages of the project. Legal acts are referred to in the following steps of the licensing project:

\section{- 13 - Draft Regulatory Reform Strategy (RRS)}

The planning discussions regarding the RRS at the initial stages of the licensing project can help to frame the discussions about what kinds of legal acts (laws, regulations, decrees, orders, and so on) will need to be drafted and adopted during the course of the licensing project.

- 16 - Legal strategy At this step, discussions that commenced earlier will need to be finalized and specific decisions about which legal act needs to be implemented at which stage of the licensing reform must be made, including drafting responsibilities and a strategy for consultation.

- 27 - Draft reform legislation/decrees

This is the intensive process of bringing the legal strategy to life - preparing initial drafts, subjecting them to stakeholder consultation, and submitting them to the decision makers.

- 28 - Implementing the legal changes (ensuring the reform is effective in practice)

This is a follow-up stage to ensure that the legal acts, once adopted, are implemented in the relevant agencies and felt by businesses.

- 32 - Regulatory Reform Unit

The Unit and the RIA system can only be established based on the legal acts that were determined and drafted in previous stages of the licensing project. 


\section{ANNEX 2 Information Collection Template for Licenses and Permits}

\section{A2.1 Background}

This "basic information collection template for licenses and permits" is designed to capture minimum information on each license and/or permit to allow for a broader inventory of all licenses/permits.

This information should be gathered by a survey of regulatory bodies and/or a trained interviewer from relevant government officials and where feasible, subjected to stakeholder (including business representative) validation. The data collection template should be completed for each and every business license/permit administered by each regulatory agency. Additional questions can be added to this template to address country or region-specific licensing/permit issues and priorities.

The information gathered through this template can also form the basis for further and subsequent diagnostic reviews and reforms of licenses and permits. Please see separate data collection templates for further information about data required to undertake one or more of the following four types of additional/supplementary diagnostic assessments:

1. the validity of a license/permit and scope for reform of the license/permit via a "guillotine" approach;

2. use of Standard Cost Model assessment;

3. information to be provided to applicants or posted on an electronic registry; and

4. a review of fees, charges and taxes collected through a license or permit.

Please note that where there is sufficient political support early-on in a licensing/ permits reform program to undertake two or more diagnostic assessments, then two or more templates can be amalgamated into one larger survey and data-collection exercise. 


\section{A2.2 Basic Information Collection Template for Licenses and Permits}

This template is used from regulators, and where feasible, validation from stakeholders.

\begin{tabular}{|c|c|c|}
\hline & Question & Response \\
\hline & $\begin{array}{l}\text { Please list the name of the } \\
\text { license/permit your agency } \\
\text { administers, including its } \\
\text { identification number (if } \\
\text { any). }\end{array}$ & \\
\hline 1. & $\begin{array}{l}\text { The purpose and objective } \\
\text { of the license (e.g., describe } \\
\text { in precise terms the problem } \\
\text { the license/permit seeks to } \\
\text { fix). }\end{array}$ & $\begin{array}{l}\text { Purpose and objective of license (e.g., safeguard } \\
\text { public health by ensuring that all shops selling food to } \\
\text { the public comply with minimum food handling and } \\
\text { storage requirements): }\end{array}$ \\
\hline 2. & $\begin{array}{l}\text { Scope of coverage of the } \\
\text { license/permit (e.g. the } \\
\text { sector or type of business/ } \\
\text { occupation that requires a } \\
\text { license/permit) and provide } \\
\text { a copy of the license and/or } \\
\text { permit application form. }\end{array}$ & $\begin{array}{l}\square \text { Sector license (which)____ and subsector } \\
\text { which)__ } \\
\square \text { Size of business (e.g., small, medium, large)? }\end{array}$ \\
\hline 3. & $\begin{array}{l}\text { The legal basis for the } \\
\text { license/permit (e.g. valid law } \\
\text { or other legal instrument) } \\
\text { and provide a copy of that } \\
\text { law/instrument. }\end{array}$ & $\begin{array}{l}\square \text { Law } \\
\square \text { Decree (or equivalent) } \\
\square \text { Administrative provision } \\
\text { (please attached copy of valid law, decree or provision) }\end{array}$ \\
\hline 4. & $\begin{array}{l}\text { Territorial scope/coverage of } \\
\text { license/permit. }\end{array}$ & \begin{tabular}{|l}
$\square$ National \\
$\square$ Provincial (which) \\
$\square$ Local (which) \\
$\square$ Other (which)
\end{tabular} \\
\hline 5. & $\begin{array}{l}\text { For this license/permit, } \\
\text { please provide the number } \\
\text { of new licenses/permits } \\
\text { issued per year. }\end{array}$ & $\begin{array}{l}\text { (e.g., } 5520 \text { new licenses were issued in 2008-09 \& } \\
5290 \text { in 2007-08) }\end{array}$ \\
\hline 6. & $\begin{array}{l}\text { The frequency of renewal of } \\
\text { license/permit. }\end{array}$ & (e.g., once a year) \\
\hline 7. & $\begin{array}{l}\text { For this license/permit, the } \\
\text { number of licenses/permits } \\
\text { renewed each year. }\end{array}$ & (e.g., 27,520 licenses were renewed in 2008-09) \\
\hline
\end{tabular}

(continued)

\footnotetext{
${ }^{44}$ License/permit number should identify the sector of economy (e.g., all businesses, or all retail shops) and where relevant the sub-sector and size of business (e.g., small retail shops selling agricultural chemicals and fertilizers).
} 


\section{Question}

8.

Describe total fees, charges or taxes collected from the license and the year these monies were collected.

9. Is information about the license/permit, application forms and other materials available on-line through an e-registry, legal gazette or other Web page? If so, please provide further information (e.g. Web address, links etc).

10. Do you consider the license/ permit is necessary?

Can this license be improved (e.g. to better achieve its purpose and objectives (reduce burdens on business, simplified etc)? If so, please provide specific suggestions and comments on how the license/permit could be improved.

\section{Response}

What is the total revenue collected from these fees/ charges associated with this license/permit (latest available figure, if known - e.g. $\$ 1.39 m$ collected in 2007-08) yes no yes no (If yes, please provide specific comments/suggestions for improvement below)

Please note here any other observations or information here: 


\title{
ANNEX 3
}

\section{Terms of Reference: Inventory of Business Licenses - Local Consultant}

\author{
Terms of Reference \\ Inventory of Business Licenses in [...]
}

\section{A3.1 Background}

The Government of [...] through the Ministry of [...] is working with [name of contracting organization] on improving the country's business environment in order to promote enterprise growth, wealth and employment creation.

This project focuses on business licenses, defined broadly as: "any ex ante authorizations required for any business activity to commence and to operate". This includes all licenses, authorizations, certificates, permits, levies, fees and other taxes imposed on business activities by any regulatory authority (including national, sectoral, provincial, and district/municipal).

\section{A3.2 Objective}

The overall objective of this exercise is to create a comprehensive inventory of all business licenses in [...]. The inventory is to include information about the legal basis, procedures, revenues, fees and costs for each individual license, and a rough assessment of the efficiency and relevance of the individual license. This will constitute an important source of information for the reform of the business licensing regime in [...]. 


\section{A3.3 Scope of Consultant's Work}

\section{A3.3.1 Identifying and diagnosing licenses.}

This is the key aspect of this exercise and it represents about $60 \%$ of the work.

Using the broad definition of business licenses above, the Consultant will identify:

- All general business licenses, which are applicable to all businesses nation-wide;

- All sectoral business licenses, which are applicable to businesses operating in a specific sector).

- All provincial and/or district/municipal licenses which are applicable to businesses operating in the following provinces: [...]

For each identified business license, using the template provided, the Consultant will collect the required information and collate it into an Excel worksheet, using one line per identified license. The information will include [to be reflected in template]:

- Name of license: official name of the license

- License number: see details in template.

- General/Sectoral: applies to all businesses (general) or to business operating in one specific sector (sectoral)?

- Name of the issuing authority: ministry, regional authority, department, unit, municipality, other?

- Territorial scope/coverage: national, regional, district, municipal?

- Legal basis: identification of authorizing law, decree, administrative provision, including the specific legal requirements set out in those regulations.

- Purpose/allowed activity: which activity is authorized by the issuance of this license? Is the primary purpose revenue raising?

- Number of steps, and estimated time necessary to obtain this license? This is at the core of the exercise. It will require a break-down of the individual steps an enterprise goes through in applying and obtaining a particular license. (Further guidance will be provided).

- Validity/Duration (time): what is the validity period of this license (if any)?

- Documentation requirements: which documents are both "legally" and "usually" requested to obtain this license? Forms and guidelines should be identified and made available. 
- Fees and calculation method: what fees must be paid to obtain this license, and how are they calculated?

- Revenue generated: What is the total revenue generated by this license, and to whom are the proceeds allocated?

- Number of licenses issued: how many licenses have been issued in the past years [specify]? Please provide data for at least one year.

- Number of eligible businesses: How many businesses constitute the target group of this license (all businesses that are required to obtain this license, but may or may not have applied for it or obtained it)? Please provide best estimate in case hard data is not available.

- Sources of information: please list the various sources consulted to provide information summarized in this form.

\section{- Person filling out this form (name).}

As part of work under this component, the information collected and generated should be aggregated and extrapolated to cover the costs and time spent on business licensing for all business in [...]. This sub-component will be led by a group of international consultants specialized in the use of the Standard Cost Model. However the role of the Consultant under this task is to ensure that the data collected is coherent and applicable to the cost- and time calculations.

\section{A3.3.2 Identifying high-priority licenses and quick-win opportunities}

This exercise represents about $20 \%$ of the work.

Work under this component will include participation in the selection of 20-30 highpriority licenses, which are considered as the most burdensome and annoying for businesses in $[\ldots]$.

Work under this component will also include the identification of licenses and licenses practices which can be subject to rapid revisions (quick wins). Quick wins will include redundant practices which can be eliminated easily, that is through executive measures, and which are expected not to create the need for lengthy political debate. The latter two tasks will take place in close cooperation with the Government of [...] counterpart.

\section{A3.3.3 Assessing licenses}

This task is complementary to information collection and should represent no more than $20 \%$ of the work. 
For each identified business license, using the template provided, the Consultant will provide a primary assessment based on the following criteria:

- Legality: Is there a sufficient legal basis for this license? If so, please name it.

- Necessity: Does this license serve health, safety or environmental protection purposes? If so, please name it.

- Efficiency: Does this license have the least impact on business activity and uses a minimum of public resources or is there a more efficient way to obtain the same result? Please explain.

- Conversion to notification: Could this ex ante license be converted into an ex post notification? Please explain.

- Silence is consent or denial: Is there a defined time limit for regulatory authority decision? Could the "silence is consent (or denial)" rule be introduced (that is if regulatory authority does not provide decision after [...] days, the license is reputed obtained (or denied) to speed up the process? Please explain.

- Threshold applicable: Would it be possible to reduce the target group, by introducing or changing an eligibility threshold (for example, instead of all firms subject to this license, say only firms with $5+$ employees are required to obtain it)? Please explain.

- Reduce reporting frequency: Should the reporting frequency be reduced to lower the administrative burden imposed on businesses? Please explain.

- Information can be obtained internally: Could all or part of the requested information be obtained internally by the regulatory authority (does another ministry or department already have it)? Please explain.

- Amalgamation with other license: Could this license be bundled or amalgamated with other licenses required from the same target group of businesses? Please explain.

- Streamlining: What other measures could be taken to improve competitiveness and reduce administrative burden for businesses?

- Source of information: Please list sources.

- Person filling out this form (name).

Based on this assessment, the Consultant will make a recommendation as to whether the license should be either: (a) kept, (b) abolished, or (c) streamlined, and provide a brief justification. 


\section{A3.4 Methodology}

This exercise relies on two main methodologies to collect information:

- Desk review of published sources: The Consultant will review official sources for legal texts, administrative decisions, municipal council decisions, etc. such as the legal gazette and any other sources regulating business operation, as appropriate.

- Interviews: The Consultant will elaborate questionnaires and conduct interviews with the relevant stakeholders, such as:

a) Investors, companies, and business associations;

b) Line ministries, regulatory agencies;

c) Provincial and municipal authorities.

For this exercise to be successful, it is essential that all efforts be made to ensure that the inventory is as comprehensive as possible. It is expected that information provided by consulted stakeholders will be cross-checked to ensure that no license has been omitted.

\section{A3.5 Deliverables}

The Consultant will deliver the following (see timeframe below for delivery dates):

- One quick wins note. The note should list 10-20 licenses considered as technically/practically easy to simplify/eliminate, (for instance, through executive order without requiring lengthy political debate). For each of the quick wins, the note should specify (i) what the problem is (ii) what revisions need to made, and (iii) the specific political/regulatory measure required to implement the measure. (that is "Minister [...] to publish the following notice in the legal gazette: [...]," etc.).

- One interim report, summarizing progress midway into the exercise (including all templates and relevant attachments completed to date).

- One draft report summarizing main findings (including the complete inventory of all templates and relevant attachments), to be reviewed by [the contracting organization].

- One final report (including the complete inventory of all templates and relevant attachments), finalized after the draft has been reviewed by [the contracting organization].

- The Consultant will participate in workshops to validate the findings at the end of this assignment.

- The reports will include in annex: 
- Inventory of identified licenses (that is one completed template per each identified license, including relevant supporting documentation, such as law/ decree, assessment, and recommendation).

- Related work carried out prior to this assignment.

- Any other relevant supporting document.

\section{- Formatting:}

- The reports will be drafted in a format agreed with [the contracting organization].

- In presenting the findings, the main focus should be placed on primary licensing data and the required analysis.

- Business licenses will be organized according to an appropriate classification.

\section{A3.6 Timeframe}

Two months [indicative] to produce a Final Report.

\section{Reporting and Consultation}

$[\ldots]$

\section{Assessment of Proposals}

[...]

\section{Consultant's Fees and Project Costs}

[...] 


\section{ANNEX 4}

\section{Terms of Reference: Standard Cost Model Benchmarking of Compliance Costs}

Terms of Reference

Standard Cost Model - Business Licensing Reform in [...]

\section{A4.1 Background on the Business Licensing Project}

[The contracting organization] is working with the Government of [... ] through the Ministry of $[\ldots]$.

One aspect of this cooperation focuses on the reform of business licenses ${ }^{45}$. The overall objective is to reduce regulatory costs and risks of doing business through streamlining and eliminating unnecessary licenses. One of the key project activities is the elaboration of a comprehensive inventory of all business licenses in [...], with the objective of preliminarily assessing the relevance and business-friendliness of these licenses and associated practices.

[The contracting organization] proposes to apply the SCM to provide reliable data about the costs and benefits of licenses identified through the comprehensive inventory. This will be an important step towards: (a) prioritization of areas of reform, and (b) assisting the Government of [...] in improving the basis for deciding on the elimination or simplification of licenses.

\section{A4.2 Objectives of the Standard Cost Model Assignment}

The overall objective of this assignment is to apply the SCM methodology to identify and measure regulatory compliance costs associated with business licenses in [...].

\footnotetext{
45 Business licenses are defined broadly as: "any ex-ante authorizations required for any business activity to commence". This includes all licenses, authorizations, permits, and fees. Licenses as defined here may also include licensing activities which de facto function as revenue generating mechanisms (that is as a tax). In other words, where the commencement of a business activity is contingent on the payment of a particular fee, this fee or tax will for the purposes of this inventory be considered a license.
} 
Application of the SCM will serve the dual purpose of providing policymakers with a quantitative measure of the impact of the current licensing regime, and of guiding priorities for specific revisions and eliminations. In other words, better information about the regulatory costs imposed on businesses will improve the transparency and economic rationality of the decision-making process of the Government of [...] in implementing the licensing review.

\section{A4.3 Consultant's Responsibilities:}

1. To make available (and appropriately adapt) a software tool ("business cost calculator"), to report and compute regulatory compliance costs. This software tool should be developed and adapted to the context of business regulation in [...]. This software tool (in the form of spread sheet) should include, but not be limited to:

a. Mapping and measuring required administrative activities

b. Isolation of specific information requirements

c. Identifying affected business segment(s), number of businesses affected, reporting frequency, and relevant cost parameters for associated administrative activities (internal/external costs)

d. In consultation with business associations, and other stakeholders: Construction of a relevant test sample and/or construction of "the normal, efficient firm"

2. To train a team of local consultants in using the above information template and software tool to identify and collect information required for an assessment of administrative compliance costs; This training may include the scrutiny and vetting of existing data and sources about business licenses in [...];

3. Within the framework developed under (2), apply a "quick scan" SCM analysis of all identified business licenses in [...] to estimate the aggregate administrative burden imposed by business licenses. ${ }^{46}$ This is expected to include validation of results with other experts and stakeholders (including businesses);

4. Within the framework developed under (2), apply a detailed SCM analysis of a selected group of 20-30 high-priority licenses, and estimate the aggregate administrative burden imposed by these licenses. This is expected to include validation of results with other experts and stakeholders (including businesses);

5. To join [the contracting organization's] team during the mission scheduled for [...], to launch the implementation of the activities above, and, where needed, take part

\footnotetext{
46 The Consultant will not be responsible for identifying and collecting data for business licenses in [...]. This effort is expected to be undertaken by local consultants under the guidance of the Consultant.
} 
in meetings with government officials and private sector representatives, as well as contribute substantive inputs to the mission's various outputs;

6. If needed, participate in a second field mission to validate findings and results from deliverables (4) and (5). Decision and timing of this field mission cannot be made at this time, but will depend on progress of data collection and government decisions on how pursue the business licensing reform.

Activities will be carried out in close cooperation with [the contracting organization], a team of local consultants responsible for data collection and preliminary analysis of business licenses, and the relevant government counterparts.

\section{MAIN ACTIVITIES, DELIVERABLES AND TIMING}

\begin{tabular}{|l|l|}
\hline \multicolumn{1}{|c|}{ Item } & Estimated workload \\
\hline Reviewed and Revised Data Collection Template & 1 day \\
\hline Training of local consultants & 2 days \\
\hline SCM framework (software tool) & 1 day \\
\hline Ad-hoc guidance of local consultants & 2 days \\
\hline Quick-scan of compliance costs for all licenses & 5 days \\
\hline Detailed assessment of steps/compliance costs for priority licenses & 10 \\
\hline Travel time & 2 days \\
\hline Miscellaneous, reporting, etc. & 7 days \\
\hline Total & $\mathbf{3 0}$ \\
\hline
\end{tabular}




\title{
ANNEX 5
}

\section{Terms of Reference: Chairperson of the Reform Committee}

\author{
WORKING COMMITTEE ON BUSINESS LICENSING REFORMS \\ Terms of Reference for the Chair
}

\section{A5.1 Background}

Many inefficient and costly licenses, permits, and certifications of businesses hamper business growth and competitiveness in [...]. The Government of [...] has decided to adopt a comprehensive approach to reforming the licensing regime.

The objective of the reform is to substantially reduce the number of licensing requirements in [... ] and, by doing so, to make the licensing regimes more simple and transparent, and focused on legitimate regulatory purposes.

Accordingly, the Government of [...] has formed the Reform Committee on Business Licensing Reforms comprising representatives of expert public authorities with cross-cutting perspectives on economic and legal reforms, including [for example] the Ministry of Commerce, the Ministry of Finance, Attorney-General's Office, and Legal Reform Commission, as well as other line ministries involved. The Reform Committee is chaired by [...], engaged by the Ministry of Commerce.

- Under the supervision of the Ministry of Commerce, the Chair is responsible for managing and directing the activities of the Reform Committee so as to ensure that the Reform Committee completes its tasks on schedule, as specified in [quote official high-level decision endorsing the mandate of the Committee].

- Under the leadership of the Chair, the Reform Committee is required to implement a comprehensive reform of the business licensing regime in [...]. This involves the review of an estimated [...] licenses, establish a permanent electronic registry 
for licenses at the Ministry of Commerce and also to put in place a mechanism for quality review of licenses in the future.

\section{A5.2 Specific Terms of Reference for the Chair}

Specifically, the Chair shall ensure that the Reform Committee:

- Designs and implements a strategic plan for the implementation of the business licensing reform in $[\ldots]$;

- Identifies individual licenses, which are required by businesses in [...] as will be or have been submitted by line Ministries and regulatory agencies and carries out such independent study as may be required to develop a complete list of all business licenses in [...];

- Subjects these licenses to a comprehensive reform within the timeframe established under the strategic plan;

- Sends a reminder and coordinate with the Ministries, regulatory agencies, and other institutions that issue licenses to obtain key information about the licenses they administer, as has been requested in Decree [...];

- Reviews the selected high-priority licenses identified by the Committee in consultation with the private sector and carries out independent assessment in order to simplify them;

- Reviews and carries out independent assessment of all other licenses identified through the comprehensive inventory. All licenses will be subjected to the following tests: Is it legal? Is it necessary from an environmental, health and safety perspective? Is it business-friendly? Is it efficiently administered?

- Assesses the revenue implications of the proposed reforms bearing in mind the budgetary implications;

- Assesses implications in terms of compliance costs for businesses as a consequence of the proposed reforms. Assessments could cover a selected number of particularly burdensome and complicated licenses;

- Liaises and consults with the private sector, line ministries and regulatory agencies to implement the comprehensive licensing reform;

- Holds consultative seminars, workshops, or meetings to ensure transparency in the process of the reform;

- Makes specific recommendations on the reforms as to which licenses are to be retained, amended, or abolished, taking into account their necessity, legality, efficiency, budgetary implications, and business friendliness; 
- Prepares the draft legislative instruments in support of recommendations and submits them to [...] by [specify date];

- Supports the final discussion and appeal processes in the Ministry of Commerce and Ministry of Finance;

- Revises final recommendations to reflect Ministry of Commerce and Ministry of Finance final decisions;

- Creates a comprehensive and central electronic registry of all licenses at the Ministry of Commerce;

- Establishes a permanent unit for quality review of new licenses in the future;

- Monitors and evaluates the implementation of the recommendations and also establishes a monitoring and evaluation mechanism within the context of the permanent unit for quality review of new licenses in $[\ldots]$;

- Carries out such other work or otherwise advises government on licensing reforms as may arise in the course of delivery of the tasks;

- Ensures coordination and consistency with the [contracting organization]'s work with the Committee and government. 


\section{ANNEX 6 \\ Outline for Decision Memos of the Reform Committee}

\section{A6.1 Summary of Main Points}

One paragraph (goals, results, benefits to [insert country here])

\section{A6.2 Our Mandate and Process}

By Ministry of Finance Decree of [cite], the Reform Committee was mandated to review and provide recommendations on improving the business environment in [...]. The Decree directed the Committee to:

- focus on licenses as a particularly damaging form of government regulation,

- use the guillotine strategy to identify and review all business licenses in [...],

- submit our recommendations by [insert date here].

We launched the "guillotine" process on schedule, worked with [...] public bodies to help them comply with the Decree, and have now completed our review of [...] licenses that were selected as potentially costly to businesses. We have prepared a Better Regulation Bill that will fully implement our recommendations.

In our review, we fully considered the information and explanations provided by the responsible bodies, and contacted many of them to invite them again to make any additional submissions they wished. A full list of consulted parties is presented in Annex 2. We carried out a thorough, transparent, and independent review, and consulted with stakeholders to determine their views on each license. The review process provided a full and fair opportunity to all interested parties to support their positions to the Reform Committee.

A draft press release is contained in Annex 1 should the Minister accept our recommendations. 


\section{A6.3 Effects of these Reforms}

- Effects on businesses: Summary from three sources: selected anecdotes, standard cost model, and model firms.

- Effects on public policies: anti-corruption, targeting on priority items,

- Effects on public revenues: summary of costs, and off-setting policies.

\section{A6.4 Our Recommendations}

Of these $[. .$.$] licenses, we make the following recommendations:$

1. [...] to be maintained without change pending further review;

2. [...] to be eliminated because they are unnecessary, outdated, illegal, or impose far higher costs than any possible benefits;

3. [...] to be simplified to achieve their goals at lower costs to businesses.

4. [...] require further review.

The licenses in each of the four categories are listed in Annex 3. The explanations for our recommendation for each license are contained in Annex 4. The necessary legal amendments to implement our recommendations are contained in Annex 5. These legal revisions are designed to be adopted as a single comprehensive package that accomplishes the recommended reforms quickly.

\section{A6.5 Our Methods}

The Committee has developed several criteria to guide its work. These criteria are based on the mandate of the working committee to reduce the burdens of business licenses. The most important of these criteria are:

1. Licenses shall be used as regulatory tools for health, safety, and environmental protection, rather than for revenue-raising purposes.

2. Reforms shall not reduce health, safety, or environmental protection, but shall aim to achieve these goals more efficiently and effectively.

3. Licenses shall not be used to determine commercial quality that is better decided in the market.

4. Licenses shall be simplified to the maximum extent possible to improve access for smaller businesses and entrepreneurs. For example, most license applications shall be reduced to one page. 
5. Application fees than shall be no higher than [...], while license fees shall be the minimum necessary to cover the cost of administering the license.

6. Duplication of information and licenses shall be entirely eliminated. Public agencies that require information shall share information among themselves, rather than imposing burdens on private businesses.

\section{A6.6 Next Steps in the Licensing Reform ${ }^{47}$}

The licensing reform is only the first step in the reforms needed to restore [...]'s competitiveness and maintain it over time. If reform stops with the "guillotine" process re-regulation will rapidly reverse the reforms.

To sustain reform, [...] must move toward international good practices of regulation. We need quality controls such as a permanent body for good regulation, systematic transparency and public consultation procedures, and capacities for regulatory impact analysis. These practices are well-accepted and recommended by the OECD and other international bodies to promote economic growth and good governance.

\section{Annex 1: Draft press release}

Annex 2: Summary of consultation process and list of all stakeholders consulted

Annex 3: Lists of licenses to be maintained, eliminated, and revised

Annex 4: Explanation of decisions

Annex 5: Full set of legal amendments

\section{Annex 6: List of additional licenses not reviewed}

\footnotetext{
${ }^{47}$ This section explains the reasons for the institutional reforms included in the deregulation bill. It includes other recommendations that were raised in the stakeholder consultation, such as the need to examine a policy on transport policy and a policy on tourism, and to promote industry self-regulation.
} 



\section{References}

Argy, Steven and Johnson, Matthew. 2003. "Mechanisms for Improving the Quality of Regulations: Australia in an International Context." Staff Working Paper, Productivity Commission, Canberra.

Australian National Audit Office. 2007. "Administering Regulation: Better Practice Guide." Canberra.

Bureau of Industry Economics. 1996a. "Business licenses - international benchmarking," 96(9). Australian Government Publishing Services, Canberra.

-1996b. "Business licenses and Regulatory Reforms," 96(9). Bureau of Industry Economics, Australian Government Publishing Services, Canberra.

Coolidge, Jacqueline. 2006. "Reforming Inspections." Viewpoint note no. 308, World Bank Group, Washington, D.C.

2010. "Tax Compliance Cost Surveys: Using Data to Design Targeted Reforms." Investment Climate IN PRACTICE note no. 8, Investment Climate Advisory Services, World Bank Group, Washington D.C.

Corthay, Laurent. 2009. "Local Regulations, Taxes, and the Business Environment: Finding the Right Balance." Investment Climate IN PRACTICE note no. 5, Investment Climate Advisory Services, World Bank Group, Washington, D.C.

International Finance Corporation (IFC). 2006a. "Business Licensing Reforms: A Toolkit for Practitioners." Small and Medium Enterprises Department, World Bank Group, Washington, D.C.

_ 2006b. "Good Practices for Business Inspections: Guidelines for Practitioners." Small and Medium Enterprises Department, World Bank Group, Washington, D.C.

_ 2007. "Strategic Communications for Business Environment Reforms." Small and Medium Enterprises Department, World Bank Group, Washington, D.C. 
2008a. "Standard Core and Supplemental Indicators for Business Enabling Environment Projects." IFC Advisory Services, World Bank Group, Washington, D.C. http://www.ifc.org/ ifcext/advisoryservices.nsf.

International Finance Corporation (IFC), German Technical Cooperation (GTZ), and U.K. Department for International Development (DFID). 2008. "Monitoring and Evaluation for Business Environment Reform: A Handbook for Practitioners." World Bank Group, Washington, D.C.

Moullier, Thomas. 2009. "Reforming Building Permits. Why Is It Important, and What Can IFC Really Do?" IFC Advisory Services, Middle East and North Africa, Cairo.

Organisation for Economic Co-operation and Development (OECD). 1995. "Recommendations of the Council of the OECD on improving the Quality of Government Regulation." Paris.

_ 2002. "Review of Regulatory Reform: Regulatory Policies in OECD Countries: From Intervention to Regulatory Governance." Paris.

Rahman, Shaela. (forthcoming, 2010). "Using Strategic Communications to Engage Stakeholders in Tax Reform." Investment Climate IN PRACTICE note, Investment Climate Advisory Services, World Bank Group, Washington, D.C.

Thomas, Cordova-Novion, Batic. 2009. "Art or Science? Measuring the Impact of Business Environment Reforms at the Subnational Level." International Finance Corporation Smartlessons, Washington, D.C.

World Bank Group. 2007. "Review of the Dutch Administrative Burden Reduction Programme." Washington, D.C.

_ 2008. "Regulatory Transformation in Mexico, 1988-2000." Case Studies on Reform Implementation Experience. Investment Climate Advisory Services, World Bank Group, Washington, D.C.

. 2009. "Lessons for Reformers: How To Launch, Implement, and Sustain Regulatory Reform. An Analysis of Six Case Studies In Developing and High-Income Countries." Investment Climate Advisory Services, World Bank Group, Washington, D.C.

_. 2010. "Policy Framework for Business Licensing Reform and Simplification." Investment Climate Advisory Services, World Bank Group, Washington, D.C.

—. (forthcoming, 2010a). "Applying the Standard Cost Model in Developing and Transition Countries: Issues for Practitioners." Investment Climate Advisory Services, World Bank Group, Washington, D.C. 
_. (forthcoming, 2010b). "Regulatory Reform in Developing Countries: the Role of Regulatory Impact Analysis." Investment Climate Advisory Services, World Bank Group, Washington, D.C.

. (forthcoming, 2010c). "Licensing Case Studies: Tourism Sector." Investment Climate Advisory Services, World Bank Group, Washington, D.C.

(forthcoming, 2010d). "Licensing Case Studies: Mining Sector." Investment Climate Advisory Services, World Bank Group, Washington, D.C. 

